\title{
An update on small molecule inhibitors of the HCV NS5B polymerase: effects on RNA synthesis in vitro and in cultured cells, and potential resistance in viral quasispecies
}

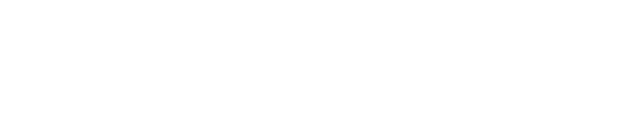

\section{S Chinnaswamy \\ $\mathrm{H}$ Cai \\ C Kao}

Department of Molecular and Cellular Biochemistry, Indiana University, Bloomington, IN, USA
Correspondence: C Kao Department of Molecular and Cellular Biochemistry, Indiana University, Bloomington, IN 47405, USA

$\mathrm{Tel}+\mathrm{I} 8128557583$

Fax +l 8128565710

Email ckao@indiana.edu

\begin{abstract}
Chronic infection by the hepatitis $\mathrm{C}$ virus (HCV) can lead to liver cirrhosis and hepatocellular carcinoma. There is currently no prophylactic vaccine against $\mathrm{HCV}$, and the treatment is currently limited to modified interferon and ribavirin. The RNA-dependent RNA polymerase (RdRp) of HCV is an attractive target for inhibitor development, and this has led to active efforts in the development of nucleoside and non-nucleoside inhibitors. The HCV polymerase is also one of the model systems for detailed analysis of how RdRp structure affects the mechanism of RNA synthesis. This review summarizes current efforts with inhibitors targeting the HCV RdRp and how the various inhibitors affect the mechanism of RNA synthesis.
\end{abstract}

Keywords: HCV infection, RdRp, nucleoside inhibitors, subgenomic replicons, ProTides, ribavirin, allosteric site

\section{Introduction and overview}

$\mathrm{HCV}$ was identified to be the causative agent of non-A-non-B viral hepatitis in the late 1970s. Infection can be through contaminated blood and all means of exposure that range from drug use to needle pricks. The virus can also be transmitted through unprotected sex. ${ }^{1}$ Approximately $80 \%$ of the acute infections will become chronic, leading to liver cirrhosis and hepatocellular carcinoma. ${ }^{2}$ Men are about twice less likely to clear the virus during the acute phase of infection than women. ${ }^{3}$ Recurring infection in the same individual can take place, likely due to reinfection by variants of the virus (quasispecies) arising from error-prone replication. ${ }^{4}$ By the year 2000 , $\mathrm{HCV}$ had infected over 170 million people worldwide and become the leading cause for liver transplants in the United States (US). ${ }^{5}$

The molecular clone of the virus was reported in 1989 by Houghton and coworkers. ${ }^{6}$ Efforts to inhibit HCV infection, with focus on HCV replication, have been active ever since. Over the past 20 years, significant progress has been made in understanding HCV biology. In addition, companies both large and small have devoted many resources to developing therapies for $\mathrm{HCV}$ infection. While pegylated interferon, which generally targets the immune system, and the purine analog ribavirin are used against $\mathrm{HCV}$ and can be effective in approximately half of the individuals, this treatment is not specific to $\mathrm{HCV}$ infection and is associated with significant side effects. ${ }^{7}$ A safe and effective inhibitor specific to $\mathrm{HCV}$ and a prophylatic vaccine against it are not yet available. Much work remains to be done on both the basic and applied aspects of HCV infection. 
This review provides an update on the mechanism of RNA synthesis by the HCV RdRp nonstructural protein 5B (NS5B), including the recent biochemical and structurefunction studies on its required role in RNA synthesis, and a summary of the NS5B inhibitors. A feature of viruses that replicate with error-prone mechanisms, however, is that resistance will rapidly develop. Using the information available in $\mathrm{HCV}$ genome databases, we examined whether strains resistant to polymerase inhibitors already exist in the genotypes and subtypes of $\mathrm{HCV}$.

\section{The hepatitis $C$ virus}

$\mathrm{HCV}$ is an enveloped virus with a positive-strand RNA genome from the Flaviviridae family. Related viruses include other important human and animal pathogens, such as dengue virus, West Nile virus, and bovine viral diarrhea virus (BVDV). The HCV genome is $\sim 9.6 \mathrm{~kb}$ in length and encodes a polyprotein of over 3,000 amino acids that is cleaved by host and $\mathrm{HCV}$-encoded proteases into 10 structural and non-structural components (Figure 1A). The 5' untranslated RNA sequence (UTR) contains an internal ribosome entry site that recruits host ribosomes to translate the viral genome. The 5'UTR, 3'UTR, and the protein-coding region have important cis-acting replication elements to regulate genomic RNA synthesis. ${ }^{8}$

Based on the paradigm established by human herpes virus and the AIDS virus, replication-associated enzymes are important targets for antiviral development. The key enzyme for HCV RNA synthesis is NS5B, the RNA-dependent RNA polymerase that replicates the viral genome. NS5B works in a membrane-associated complex that also contains NS3 (protease-helicase), NS4A (NS3-coactivator), NS4B (key protein for the formation of the membranous web that houses the replication complex), and NS5A (a dsRNA-binding

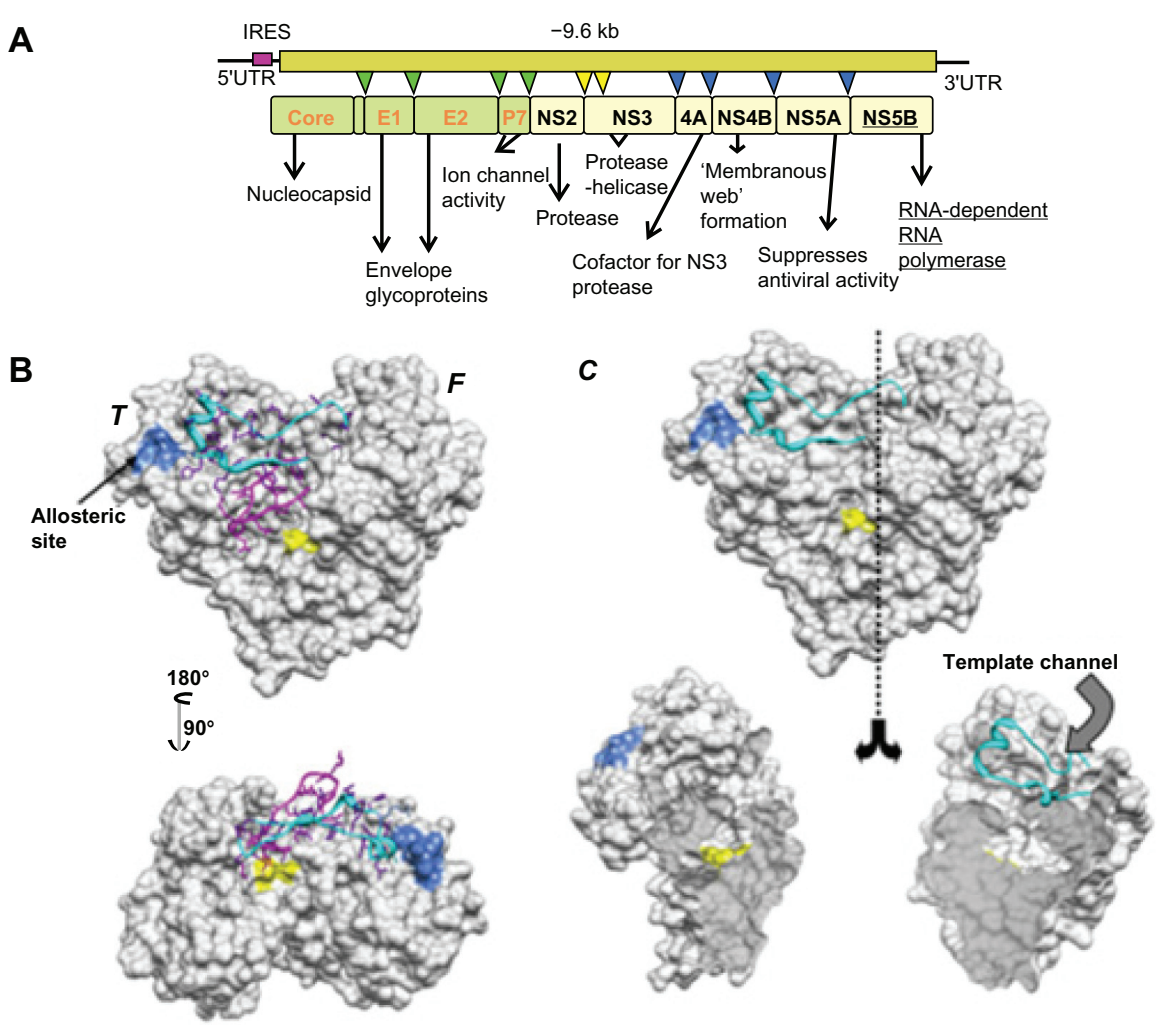

Figure I HCV polyprotein cleavage and the closed conformation of NS5B. A) The organization of the HCV genome and the scheme for HCV polyprotein cleavage. The positive sense RNA is schematically depicted on the top in mustard yellow. The internal ribosome entry site (IRES) is depicted as a purple box in the 5' UTR. The polyprotein sequence is shown in green for structural proteins and yellow for non-structural proteins. The green inverted triangles represent cleavage by the host signal peptidases. The core protein is further processed at its C-terminus by the ER signal peptide peptidase (little blue arrow). The NS2 protease separates itself from NS3 and the remaining polyprotein by autoproteolysis (yellow triangle). The remaining polyprotein is cleaved by NS3 protease by using NS4A as the cofactor (blue triangles). The putative functions of the individual proteins are indicated below each protein. B) The crystal structure of HCV NS5B $\triangle 35$ (PDB ID IQUV) shown as surface representation with the fingers (F), thumb ( $T$ ) and palm (P) domains. The allosteric GTP binding site in the thumb domain of HCV NS5B is colored light blue. This site is a low affinity GTP binding site identified by crystal soaking experiments, with an apparent $K_{d}$ of 200-400 $\mu \mathrm{M}^{33}$ The residues involved with GTP binding at this site are P495, V499, R503, R32, and S29. R32 and S29 are at the apex of the $\Delta \mathrm{I}$ loop. The two loops that regulate RNA synthesis are shown as ribbons. The $\Delta \mathrm{I}$ loop is in cyan and the $\Delta 2$ loop is in magenta. The active site GDD residues in the palm domain are colored yellow. C) The template channel in NS5B is a region within the closed conformation of the enzyme that starts at the top in between the junction of the thumb and fingers domains and extends into the active site and emerges out in between the palm and thumb domains. The bottom image shows a cut away representation of NS5B exposing the template channel along a vertical axis (dashed line in top image). 
protein that stimulates NS5B activity as well as inhibits cellular signaling)..$^{9,10}$ These subunits can recognize important cis-acting regulatory sequences in the $\mathrm{HCV}$ genome. ${ }^{8}$ These proteins also have additional roles during the infection process that are independent of RNA synthesis, such as interference with the signals for the host innate immune responses and perturbation of normal cell cycle control. ${ }^{11-14}$ Therefore, targeting the viral replication enzymes could prevent the virus from affecting normal cellular processes as well as inhibiting HCV RNA synthesis.

\section{Systems to study HCV replication}

Ever since the identification of the viral origin of Hepatitis $C$, a number of significant challenges have hampered the development of effective antivirals. , $^{6,15,16} \mathrm{HCV}$ did not have a model system to study its infection since it could only infect humans and chimpanzees. This required a number of less than optimal substitutes, including immune-defective mice with transplanted human livers. ${ }^{17} \mathrm{~A}$ recent advance may result from the identification of the tree shrew as a host, ${ }^{18}$ although the efficacy of this system remains to be tested.

Until 2005, HCV could not replicate efficiently in cultured cells. In 1999, Lohmann et al developed a substitute system for HCV, a selectable subgenomic replicon system. ${ }^{19}$ Subgenomic replicons are viral mini-genomes that lack the genes encoding structural proteins, but have genes encoding fully functional nonstructural proteins that can express reporter genes in the human hepatocyte cell lines, Huh7 and its derivative Huh7.5. Huh7.5 was found to have a defect in the innate immune receptor, RIG-I. ${ }^{20-22}$ Mutations in NS5A, NS3, and NS4B were necessary for the replicons to multiply in cells to higher levels (named as replication enhancing mutations or REMs). ${ }^{23}$ These adaptive mutations helped the full-length viral genome to replicate in cells, but they failed to produce infectious viral particles. ${ }^{24}$ Nonetheless, the HCV replicon systems opened the door for cell-based screens for $\mathrm{HCV}$ inhibitors and for the identification of mutations that are altered in their responses to inhibitors.

In 2005, a study of the full HCV infection beyond RNA replication was made possible by the isolation of a genotype 2a HCV strain which caused fulminant hepatitis in a Japanese patient. This strain was named JFH1. ${ }^{25,26} \mathrm{JFH} 1$ can successfully infect Huh7.5 cells and multiply without the need for REMs. Features of the JFH1 virus, however, are that it is not pathogenic in chimpanzees, ${ }^{27}$ and it is not a candidate vaccine strain because of the prevalence of the $1 \mathrm{a}$ and $1 \mathrm{~b}$ $\mathrm{HCV}$ infection in the western world. This leaves the subgenomic replicon system along with NS5B protein expressed from heterologous systems as useful tools to understand the mechanism of RNA synthesis as well as for developing inhibitors targeting NS5B.

\section{NS5B, the RNA-dependent RNA polymerase of HCV}

Biochemical assays for RNA synthesis by NS5B have facilitated antiviral drug development and the complementary efforts to better understand the mechanism of HCV RNA synthesis. As with other polymerases, the analogy of a human right hand is useful in describing the domain architecture of NS5B with the thumb, the fingers, and the palm domains. ${ }^{28,29}$ NS5B has the characteristic divalent metal binding motif that contains two consecutive aspartates in the palm domain. ${ }^{30}$ The thumb and fingers domains are used to help regulate nucleic acid binding (Figure 1B). The 591-residue NS5B protein has a hydrophobic C-terminal tail of approximately 21 amino acids that tether the protein on to the membranes. These residues are dispensable for enzymatic activity, but needed for viral replication in cells. ${ }^{31,32}$ NS5B lacking the C-terminal 21 residues (referred to as $\Delta 21$ ) is widely used in biochemical, structural, and inhibitor studies because it can be purified to homogeneity and does not require detergents in the buffer. ${ }^{31,33-37}$ Furthermore, no significant differences between the enzyme kinetics of the full-length versus $\Delta 21$ enzymes were observed. ${ }^{31,38}$ Another version that lacks 55 residues (referred to as $\Delta 55$ ) was initially used for biochemical and structural characterizations. ${ }^{39}$ However, the $\Delta 55$ enzyme lacks a portion of the sequence that lines the active site, and its use has decreased over the years.

The first characterization of RNA synthesis by the HCV $\mathrm{RdRp}$ reported a primer-dependent activity wherein the non-HCV template formed a partial hairpin at the 3 ' end to allow the polymerase to extend by a copy-back mechanism. ${ }^{40}$ Lohman et $\mathrm{al}^{41}$ demonstrated that the recombinant $\mathrm{RdRp}$ can copy the full-length HCV plus strand genomic RNA by the same mechanism. Although these works established the polymerase activity of HCV RdRp, a copy-back mechanism cannot be relevant to HCV RNA replication since it would result in a deletion or other covalent modifications of the genome. A related RdRp from the BVDV was reported to initiate RNA synthesis by a de novo mechanism, suggesting the possibility that a similar de novo initiation mechanism existed for HCV RdRp. ${ }^{42}$ De novo initiation was soon demonstrated for a recombinant HCV NS5B from both short synthetic RNA templates as well as from full-length and truncated plus-strand HCV genomic RNA. ${ }^{43-46}$ A stable secondary structure is needed at the 3' end of the template RNA that will 
promote more efficient de novo RNA synthesis, and a purine triphosphate, especially GTP (guanosine 5'-triphosphate), is the preferred initiating nucleotide..$^{35,43,46,47}$ High levels of GTP but not other NTPs (nucleotide triphosphates) have been found to stimulate de novo initiation. ${ }^{48}$

\section{Structural and functional insights}

A seminal start for the antiviral development effort against HCV was the elucidation of the structure of NS5B by $\mathrm{X}$-ray diffraction of the C-terminally truncated versions of NS5B by three independent groups in $1999 . .^{39,49,50}$ The palm domain has the conserved GDD residues that coordinate the divalent metal ions and carry out the nucleotidyl transfer reaction. Several crystal structures of NS5B in complex with inhibitors, NTPs, and a 5-nt ssRNA have been subsequently reported, but thus far no structural information is available for the ternary complexes involved in initiation and elongation. . $^{51-55}$

A unique feature of the HCV RdRp and that of related viral RdRps is that the thumb and the fingers domains are bridged by two loops called the $\Delta 1$ loop and $\Delta 2$ loop $^{28,56}$ (Figure 1B). These two loops are responsible for the closed conformation of the enzyme that results in a complete encircling of the active site from the front side (front side as viewed with the thumb domain at the left and fingers domain at the right side of the viewer in Figure 1B). The back side is covered by another loop called the $\beta$ loop that forms part of the template channel. This loop extends toward the metal coordinating residues in the active site. This encircling of the active site will result in a well-defined template channel that can accommodate a ssRNA, but not a dsRNA (Figure 1C). ${ }^{54}$

Since the ternary complex of the RdRp will contain dsRNA, the closed structure solved by X-ray crystallography should transition to the more open one during the elongation stage of RNA synthesis. It was initially proposed that the $\beta$ loop is used by the polymerase for this transition. ${ }^{49}$ In fact, a study showed that a deletion of eight residues in the $\beta$ loop allowed productive elongation from dsRNA templates whereas the wild type (WT) enzyme was not able to perform primer extension. ${ }^{57}$ However, according to other predictions, if the $\beta$ loop is pushed out of the template channel to accommodate the dsRNA, a large adjustment to the thumb domain should be necessary. ${ }^{39,55}$

The $\Delta 1$ loop in HCV NS5B contains about 35 residues (Figure 1B and 1C) and is largely a coil structure except for the region that contacts the thumb domain where a small helix (helix A) fits into a pocket defined by amino acids H428, I432, W397, A396, and several other residues. Amino acids in this loop are highly conserved and make important hydrophobic contacts with the thumb domain that will define the contours of the template channel. ${ }^{55}$

The model that the unique closed conformation of the enzyme was the one engaged in RNA synthesis was based on the ternary structure of the RdRp from phage $\phi 6 .{ }^{58}$ Further work found that mutations that disrupted the $\Delta 1$ loop and thumb domain interactions and therefore altered the closed conformation of the enzyme, were detrimental to RNA synthesis. ${ }^{59}$ Therefore, it was speculated that this interaction is stable during the catalytic cycle of polymerization and that it may be used for the 'clamping movement' of the polymerase on the RNA template during elongation. ${ }^{59}$ If true, this mechanism would be unique to $\mathrm{HCV}$ and related viral RdRps that have a $\Delta 1$ loop-like structure since other template-dependent polymerases do not possess a thumb and fingers bridging interaction during elongative RNA synthesis. ${ }^{29,60}$ However, an 'open conformation' of a genotype 2a NS5B was crystallized by Biswal et al. ${ }^{51}$ In this structure, the enzyme deviated from the closed structure due to changes in the interactions between the apex of the $\Delta 1$ loop and the thumb domain. The apex of the $\Delta 1$ loop formed a $\beta$ sheet instead of the $\alpha$ helix that is evident in all other reported crystal structures of NS5B. This suggests that the tip of the $\Delta 1$ loop and thumb domain interactions may not be stable in solution. Additional biochemical experiments showed that an enzyme that has a deletion at the apex of the $\Delta 1$ loop was capable of primer extension from short RNA templates suggesting that an absolutely closed conformation of NS5B may not be a prerequisite for its catalytic activity. ${ }^{61}$

\section{The allosteric site of NS5B}

GTP is known to stimulate RNA synthesis by HCV NS5B at high concentrations. ${ }^{48,55}$ Surprisingly, crystal soaking experiments identified a second site in the HCV NS5B that can bind GTP ${ }^{33}$ (Figure 1B). The first site that is involved in polymerization exists in the palm domain, binds to all four NTPs, and has an affinity for GTP in the sub-micromolar range. The second site is found in the thumb domain adjacent to the pocket that interacts with the $\Delta 1$ loop and does have specificity for GTP. GTP bound to this site with an estimated Kd between $200-400 \mu \mathrm{M} .{ }^{33}$ This latter site will henceforth be referred as the allosteric site.

Cai et $\mathrm{al}^{62}$ performed a systematic mutagenesis analysis of the allosteric site and found that none of the point mutations affected de novo initiation activity of NS5B in vitro. However, all of the mutations affected the replication of subgenomic replicons to various degrees, suggesting that the 
allosteric site plays a crucial role in HCV replication in cells. By being adjacent to the $\Delta 1$ loop binding pocket in the thumb domain, the allosteric site could regulate the conformations of the NS5B that are relevant for RNA synthesis and possible interaction with cellular proteins (Figure 1B). Consistent with this model, residue H502 had been shown to be essential for homomeric interactions between NS5B subunits. ${ }^{63}$ In addition, the allosteric site overlaps with the critical residues required for binding of inhibitors..$^{64,65}$

\section{Mechanism of RNA synthesis by HCV NS5B}

In vitro RNA synthesis by the NS5B can be divided into at least four sequential stages: 1) assembly of productive initiation complexes (de novo initiation or primer extension complexes), 2) nucleotidyl transfer to synthesize the first or first few phosphodiester bonds, 3) processive elongation, and 4) termination of RNA synthesis. In vitro, the RdRp can also switch templates before termination, although the relevance of this activity in cells in not known. Under certain conditions, the HCV and other viral RdRps can also add nontemplated nucleotides to the 3 ' terminus of the template. ${ }^{34,66}$ While this activity can be relevant in the repair of deleted ends of the RNA, its biological relevance to HCV infection remains to be demonstrated. Finally, a property of RNA polymerases is the excision of an incorporated nucleotide in the presence of excess pyrophosphate and the HCV RdRp has been reported to also contain this activity. ${ }^{67}$

Although the crystal structures of the HCV RdRp provided an excellent starting point for understanding $\mathrm{HCV}$ RdRp RNA synthesis, the static closed conformation soon became insufficient to account for the requirements for RNA-dependent RNA synthesis. First, the template channels in the HCV RdRp and in $\phi 6$ polymerase were too narrow to accommodate the partial RNA duplexes that must be formed as a consequence of RNA synthesis. ${ }^{55,61,68}$ Second, Ranjith-Kumar et al showed that the HCV RdRp could direct de novo initiated RNA synthesis from a circularized template. ${ }^{69}$ Since a circularized RNA cannot thread a terminus into the active site, this observation suggests that the HCV polymerase could undergo a transition from the closed to an open conformation before template recognition. Third, in vivo, cyclophilins, a class of peptidyl-prolyl isomerases, are needed by NS5B likely to assist in template loading. ${ }^{70}$ All of these results suggest that the closed conformation of the HCV RdRp is not the form that mediates a full round of HCV RNA synthesis either in vitro or in cells. Even structural analyses support a more dynamic model for HCV
RNA-dependent RNA synthesis. Biswal et al were able to capture a partially open conformation of the HCV RdRp using X-ray crystallography. ${ }^{51}$ In addition, the BVDV RdRp was demonstrated to form a more open conformation due to the interaction between two subunits through the structural equivalent of the $\Delta 1$ loop. ${ }^{56}$

In in vitro conditions, NS5B can synthesize RNA by de novo initiation or primer extension mechanisms (Figure 2A). The $\mathrm{K}_{\mathrm{M}}$ values for the NTPs involved in these two mechanisms are significantly different, suggesting that different conformations of NS5B are involved in these two modes of RNA synthesis. ${ }^{71}$ Studies with the dengue virus RdRp also support this hypothesis wherein a higher temperature favors an open conformation of RdRp that could carry out primer extension, but not de novo initiation. ${ }^{72}$

Two models for HCV RdRp RNA synthesis are proposed based on the oligomeric state of the protein (Figure 2B): the closed monomer model and the oligomeric model. The closed monomer model posits that intramolecular interactions involving the $\Delta 1$ loop, $\Delta 2$ loop, and the $\beta$ loop along with the $\mathrm{C}$-terminal tail allow the polymerase to overcome the rate

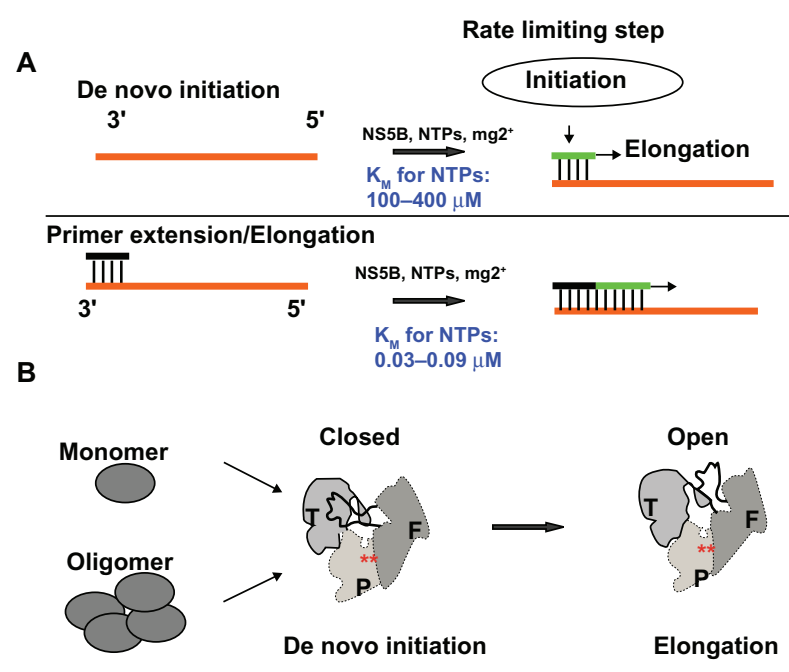

Figure 2 RNA synthesis mechanisms in NS5B. A) De novo initiation vs primer extension/elongation in NS5B. De novo initiation involves the recognition of the 3' end of the template RNA (red) by NS5B and initiation of RNA synthesis without the need for a primer. De novo initiation has two steps: initiation (involves the synthesis of a primer of 5-6 nt, shown as green) and elongation. Initiation is thought to be rate limiting. By contrast primer extension/elongation involves extension of a primer (black) along the length of a template (red) from a preformed primer-template RNA complex akin to the elongation step in de novo initiation. The newly extended RNA is shown as green. The $K_{M}$ values shown are obtained from Ferrari et $\mathrm{al}^{70} \mathbf{B}$ ). Two models for de novo initiation by NS5B. The first model is based on the assumption that the $\Delta \mathrm{I}$ loop and thumb domain interactions are stable in a monomer. The second model is based on the idea that the $\Delta \mathrm{I}$ loop and thumb domain interactions are stabilized by oligomeric interactions between NS5B subunits. In both models, the closed conformation of the NS5B monomer is the form that is capable of de novo initiation, while steric clashes that result in the template channel when a dsRNA product is formed will push the enzyme to go into an open form where the $\Delta \mathrm{I}$ loop loses its original interactions with the thumb domain. T, P, and F refer to thumb, palm, and finger domains, respectively. 
limiting initiation step of RNA synthesis and provide steric fit for specific recognition of the template RNA (Figure 2B). Once a nascent RNA reaches a sufficient length ( $\sim 6-8 \mathrm{nt})$, the polymerase must transition to an open conformation likely by loosening its $\Delta 1$ loop and thumb domain interactions, after which, elongation ensues in the open conformation. ${ }^{61}$ This mechanism may be relevant in several other RdRps which have the $\Delta 1$ loop like structures that connect the fingers and the thumb domains. ${ }^{28,61}$

The oligomerization model posits that the closed conformation of NS5B is maintained by homomeric interactions between NS5B subunits, likely by stabilizing the $\Delta 1$ loop and thumb domain interactions. Since the closed conformation is only required for the initiation of RNA synthesis and multiple active sites may not be needed for de novo initiation ( $\mathrm{S}$ Chinnaswamy, $\mathrm{C}$ Kao, manuscript in review), the oligomeric interactions between the NS5B monomers are thought to involve more than one interface as shown by Wang et al. ${ }^{73}$ Interestingly, genotypic differences have been reported in oligomeric properties of NS5B and may have clinical implications. ${ }^{74}$ For example, polymerase inhibitors that interfere with NS5B oligomerization may not be effective on certain HCV genotypes that rely to a lesser degree on NS5B homomeric interactions in order to overcome the rate limiting initiation step of RNA synthesis. The oligomeric model for RNA synthesis is also proposed for the wellstudied poliovirus RdRp and for the norovirus RdRp. ${ }^{75,76}$

\section{HCV NS5B inhibitors}

Inhibitors of HCV NS5B can be broadly classified into four classes based on their chemical composition and/or mode of action. The first class consists of nucleoside or nucleotide analogs that act as competitors of NTPs during RNA synthesis. This class also includes the purine analog ribavirin, the only Food and Drug Administration (FDA) approved small molecule drug for the treatment of HCV, which has pleiotropic effects on both the cellular and viral enzymes (see below). The second class consists of non-nucleoside inhibitors that allosterically target the NS5B, and the majority of these inhibit the initiation stage of RNA synthesis. A third, small class has a distinct mechanism of inhibition in that its members covalently modify the residues near the active site of NS5B and inhibit its activity and some act by chelating the divalent metal ions needed by NS5B. A fourth and rapidly emerging class consist of compounds that target cellular proteins needed for HCV polymerase function. This class may have advantages in that the virus cannot rapidly evolve resistance to the inhibitors.

\section{Nucleoside inhibitors ( $\mathrm{NI})$}

Nucleoside or nucleotide mimics are usually designed to cause premature chain termination during viral nucleic acid synthesis or to increase error in polymerization. Conversion of the nucleoside prodrugs to their triphosphorylated forms is required for inhibitory activity. Several nucleoside analogs have been studied in cells expressing HCV subgenomic replicons, and also in animal models.

\section{Ribose C2' modifications}

Nucleoside analogs with modifications at the C2' position of ribose may hold more promise as antivirals. A number of these compounds have progressed to clinical trials and can act in synergy with the interferon-ribavirin combination therapies. ${ }^{77} 2$ ' ribose modification of cytidine (2'-O-methyl) and adenosine (2'-C-methyl) (Figure 3) will result in potent inhibition of replication by the HCV subgenomic replicons by acting as 'non-obligate' chain terminators of RNA synthesis. That is, although the analogs retain the ribose 3'OH group for phosphodiester bond formation, they can induce structural constraints in the active site that lead to chain termination. ${ }^{78}$ A resistant mutation in NS5B S282T was identified for the 2 ' ribose modified nucleoside analogs (Figure 4). ${ }^{79}$ Biochemical characterization revealed that the resistance was due to reduced affinity to the compound and also an increased ability by the mutant polymerase to incorporate the nucleotide analog during elongation.

Migliaccio et al reported good oral bioavailability of 2'-C-methyl guanosine (2'-C-mG) and also synergistic inhibitory activity with interferon. ${ }^{79}$ However, a 7 -deaza modified 2'-C-mG suffered from poor cell penetration and inefficient phosphorylation by cellular kinases whereas a 7-deaza modification of 2'-C-methyl-adenosine resulted in a compound with improved pharmacokinetic properties and lower toxicity than its unmodified form. ${ }^{80} \mathrm{MK} 0608$ (7-deaza2'-C-methyladenosine) has an $\mathrm{EC}_{50}$ of $0.25 \mu \mathrm{M}$ in replicons and has showed promising results in animal studies. ${ }^{81}$ PSI6130 (2-deoxy-2'fluoro-2'-C-methylcytidine) and its prodrug form, $\mathrm{R} 7128$ that has a ribose 2' fluoro group modification have $\mathrm{EC}_{50} \mathrm{~s}$ of $\sim 4.5 \mu \mathrm{M}$ against the HCV NS5B subgenomic replicon and may be specific since they did not affect the BVDV subgenomic replicon. ${ }^{82}$

\section{Other nucleoside modifications}

In general, ribose 3'-deoxy modified nucleoside analogs, especially 3'-deoxy-GTP and 3'-deoxy-CTP (cytidine triphosphate), are good chain terminators of HCV NS5B RNA elongation in vitro, but they suffer from poor activation 


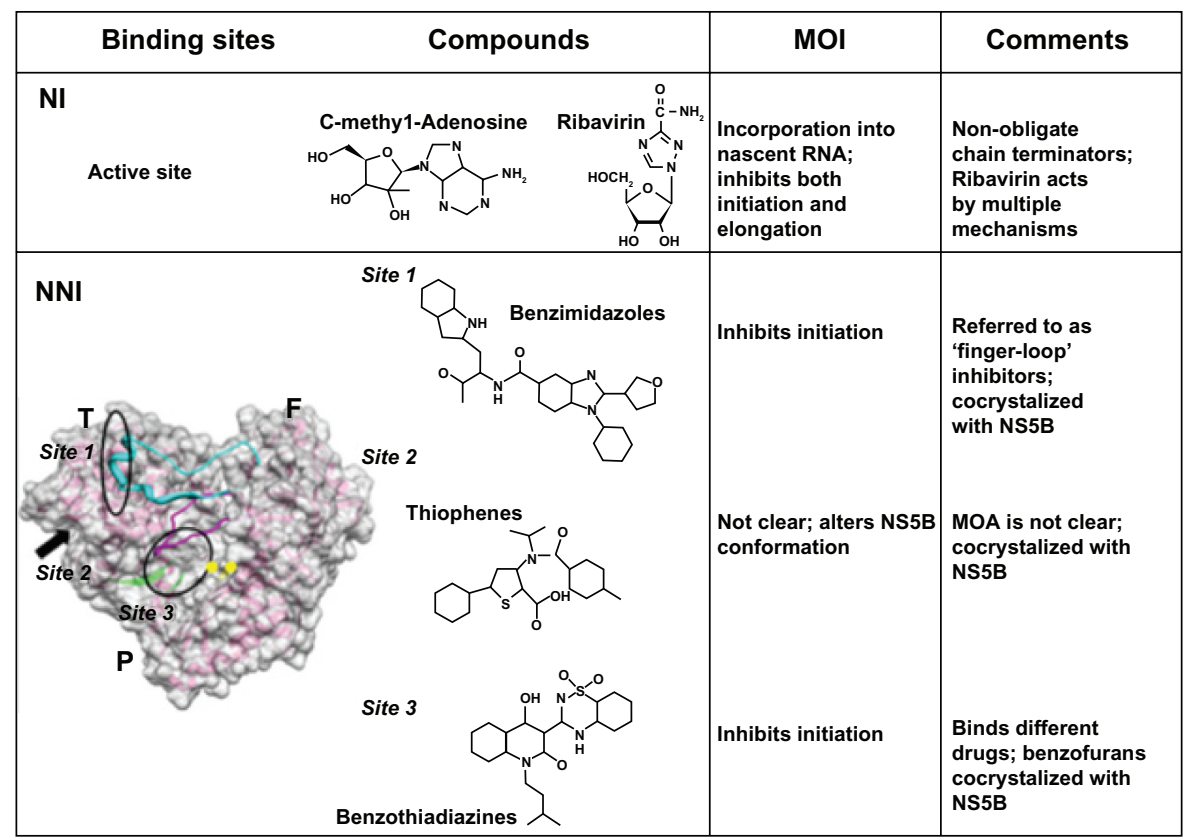

Figure $3 \mathrm{NI}$ and NNI of NS5B. The figure tabulates the different $\mathrm{NI}$ and NNI of NS5B into their proposed or identified binding sites and their mechanism of inhibition (MOI). The NI bind in the active site as they are incorporated into the nascent RNA. NNI bind to three different sites in the polymerase. Site I overlaps with the binding region at the apex of the $\Delta \mathrm{I}$ loop on the thumb domain, while Site 2 is a hydrophobic cleft found $\sim 10 \AA$ beneath Site I. Site 3 , unlike the other two sites, is not on the surface of the enzyme and is located in the template channel and binds to different drugs. Residues from 360-370 are commonly referred to as the 'primer-grip' site as this region is thought to interact with the primer in an elongating polymerase (colored green). Benzofurans that are in Site 3 class bind to this region. Benzothiadiazines are thought to bind to residues close to the active site (like M4I4) in Site 3. The divalent metals that bind in the active site are shown as yellow spheres. The representative scaffolds of the different drugs are shown. T, P, and F refer to thumb, palm, and finger domains, respectively.

into their triphosphate forms in cells. ${ }^{83} \mathrm{~A}$ 4' ribose-modified nucleoside, 4' -azidocytidine (R1479), and the modified version of 4'-azidocytidine have also been reported to be able to chain-terminate RNA synthesis by HCV NS5B. ${ }^{84}$ This analog had a similar $\mathrm{IC}_{50}$ (in the range of $1.12-1.3 \mu \mathrm{M}$ ) to that of 2'-C-methyl-cytidine in subgenomic HCV repliconexpressing cells, and concentrations as high as $2 \mathrm{mM}$ were not toxic to cells. ${ }^{84}$ The S282T mutation did not affect the inhibitory effect of R1479. However, this analog has been discontinued due to safety issues. ${ }^{81}$

2'-C-methylcytidine (NM107) was found to inhibit BVDV polymerase with a $\mathrm{K}_{\mathrm{i}}$ of $160 \mathrm{nM} \cdot{ }^{81}$ However, this drug did not have good oral bioavailability. A modification at the $3{ }^{\prime} \mathrm{OH}$ of ribose, 3'-O-valinyl-2'-C-methylcytidine (valopicitabine or NM283) led to enhanced pharmacokinetic properties and has showed promise initially in clinical studies in HCV infection especially when combined with peg-IFN and ribavirin. ${ }^{81}$ However, due to associated serious side effects the FDA has suspended clinical trials for NM283 in the US. ${ }^{77}$

Dihydroxypyrimidines that are thought to be pyrophosphate mimics have been reported to affect RNA synthesis by the HCV NS5B protein. ${ }^{85,86}$ NS5B, like other RNA polymerases, can hydrolyze inhibitors incorporated into the nascent RNA strand by essentially reversing the polymerase reaction in the presence of increased pyrophosphates. Therefore, inhibitors that can bind the pyrophosphates could impact HCV resistance to nucleotide or nucleoside analogs. Mutations G152E and P156L will decrease the ability of dihydroxypyrimidines to act as competitive inhibitors in HCV replicon replication. ${ }^{85}$

\section{Ribavirin}

The purine analog ribavirin is an FDA approved drug for treatment of HCV in humans and has been in use for more than a decade. In conjunction with pegylated interferon, ribavirin can clear $\mathrm{HCV}$ in approximately $50 \%$ of the treated patients, but many side effects exist. ${ }^{87}$ Ribavirin may act by more than one mechanism, including by modulation of the immune response and an increase in the polymerase mutation rate when incorporated, causing an 'error catastrophe' ${ }^{87}$ Ribavirin may also act by inhibiting the host IMP dehydrogenase, which will in turn lower the GTP level in the cell. Interestingly, a $\mathrm{Y} 415 \mathrm{~F}$ mutation has been mapped in the template channel (Figure 4A) that can confer resistance to this purine analog, providing evidence for ribavirin binding to NS5B. ${ }^{88}$

Resistance mutations to NI include S282T, S96T, and N142T (Figure 4A). ${ }^{79,89}$ The S282T mutation confers resistance to 2'-C-methyl-cytidine and 2'-C-methyl-adenosine. 
A

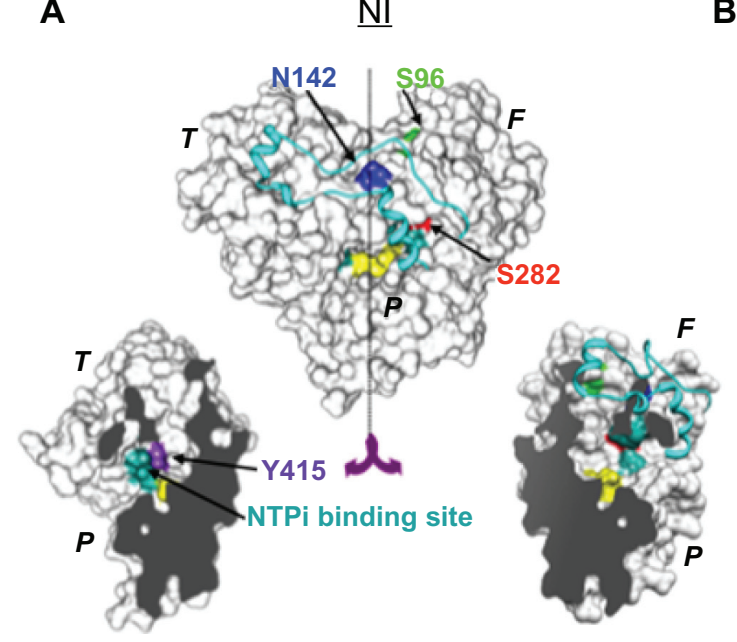

B
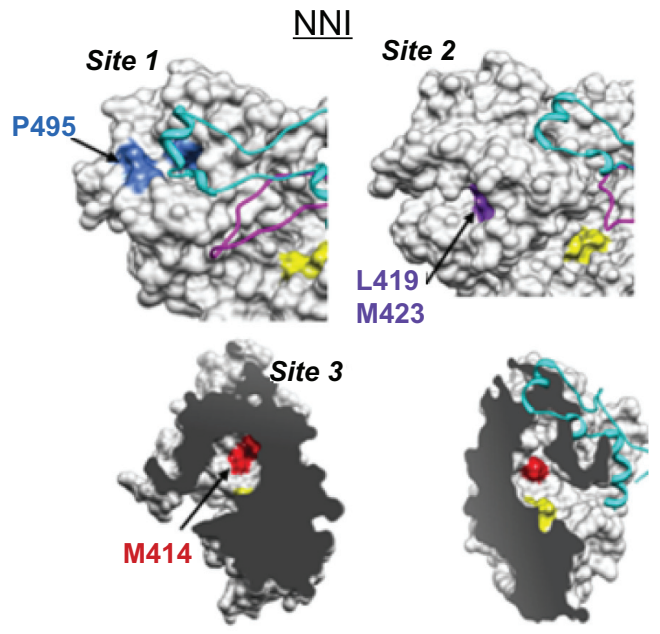

Figure 4 Locations of resistance mutations that arise in NS5B structure (PDB ID IQUV) in the presence of different NI and NNI. A) S282T is a resistance mutation that arises in response to 2'-C-methyl-cytidine and 2'-C-methyl-adenosine nucleoside analogs; residue S282 is indicated in red. S96T and NI42T mutations are resistant to 4'-azidocytidine (RI479) and are shown in different colors. Y4I5F is a resistance mutation commonly observed in response to ribavirin therapy. The $\Delta \mathrm{I}$ loop is shown in cyan and the active site GDD residues are colored yellow. The NTPi binding residues in the active site ${ }^{88}$ are shown in light green. The bottom image shows the cut away representation of the polymerase exposing the template channel and the NTP tunnel. B) Resistance mutations arising in NS5B in the presence of NNI. Mutants conferring resistance to benzothiadiazines (NNI, Site 3) include M4I4T, C45IR, G558R, and H95R, but only M4I4 is shown in the cut away representation of the polymerase. H95 is located outside of the template channel whereas other mutations are within the template channel. The $\Delta \mathrm{I}$ loop is in cyan and $\Delta 2$ loop is in magenta and the active site GDD residues are in yellow. T, P, and F refer to thumb, palm, and finger domains, respectively.

S282T also reduced the replicative capacity of subgenomic repicons to $\sim 20 \%$ to that of $\mathrm{WT}^{79}{ }^{7} \mathrm{~S} 96 \mathrm{~T}$ and N142T mutations confer resistance to R1479, and their presence severely debilitates subgenomic replicon capacity ${ }^{89}$ and does not confer cross resistance to 2'-C-methyl-cytidine, suggesting a specific interaction in the binding pocket. The $\mathrm{S} 282$ residue is in close proximity to the residues in NS5B that bind to the NTPi (initiation nucleotide) (Figure 4A). ${ }^{90}$ Mutations involving the NTPi-binding residues have yielded polymerases that are decreased in de novo initiation, but unaffected for primer extension activity. ${ }^{91}$ This also suggests that the NTP binding pocket in the active site altered during elongation than during de novo initiation, consistent with the idea of a specific NTPi binding pocket during initiation. Residue S282 therefore has a specific interaction with the nucleotide analog inhibitors in the NTP binding pocket in order for a mutation at this residue to confer resistance. None of the mutations conferring resistance to NI lie outside the template channel (Figure 4A), suggesting that they do not allosterically influence the polymerase function, unlike non-nucleoside inhibitors (see below). Dinucleotide analogs targeting de novo initiation by NS5B have also been reported, ${ }^{92}$ but no progress has been reported in their development.

\section{ProTides}

A significant issue pertaining to all nucleoside-based inhibitors is that they must be converted into the triphosphorylated form to be potent competitive inhibitors of nucleotide incorporation. ${ }^{93}$ For HCV, cellular kinases are responsible for this conversion and the addition of the first phosphate (to form the nucleoside monophospate) is the rate-limiting step. One solution to increase conversion to the active inhibitor is to generate compounds that can be activated by cellular enzymes to contain a 5 ' monophosphate. However, these analogs need to contend with poor permeability through cellular membranes by the addition of lipophilic groups to the portion of the molecule that will be cleaved. Phosphoramidate analogs that can be converted to nucleotides, termed ProTides have shown recent promise. ProTides with 4'-azido modified uridines and inosines as well as lipophilic moieties can inhibit $\mathrm{HCV}$ replicon replication with low micromolar $\mathrm{EC}_{50}$ and $\mathrm{CC}_{50}$ (cytotoxicity) levels greater than $100 \mu \mathrm{M} .{ }^{94,95}$ In combination with other chemical motifs known to be effective against HCV, ProTides could provide the next generation of NI with improved efficacy. This technology should be applicable to other nucleotide analogs and has already shown promise with DNA methyltransferases. ${ }^{96}$

\section{Non-nucleoside inhibitors (NNI)}

Several NNI have been identified that primarily target the initiation phase of RNA synthesis by NS5B, likely by preventing critical conformational adjustments in the enzyme needed for productive RNA synthesis. The NNI target two sites on the surface of the polymerase and one within the template channel. Site 1 involves the $\Delta 1$ loop and thumb domain interface ('finger-tip' region). Site 2 is in a pocket 
in the thumb domain that is present beneath Site 1. Site 3 is in the template channel, and involves the 'primer-grip site' and the $\beta$ loop (Figure 3).

\section{Site I}

Benzimidazoles and indole derivatives bind to Site 1 and inhibit the initiation stage of RNA synthesis by NS5B. ${ }^{53}$ Benzimidazoles were identified by Boehringer Ingelheim to inhibit NS5B noncompetitively with NTPs at low micromolar $\mathrm{IC}_{50}$ values..$^{53,97,98}$ This site also overlaps with the allosteric site that putatively binds $\mathrm{GTP}^{33}$ (Figures 3 and 1B). Inhibitor binding at this site results in disruption of the inter-domain communication and displacement of the $\Delta 1$ loop. ${ }^{53}$

Benzimidazole and indole derivatives did not inhibit NS5B during the elongative mode of RNA synthesis and also were ineffective on preformed NS5B-RNA complexes. ${ }^{64,99}$ Interestingly, the presence of RNA was required for binding of benzimidazoles to NS5B while preincubated binary complexes that should cause a stepwise loss of $\Delta 1$ loop-thumb domain interaction rendered the complex more resistant to the inhibitory effects of the benzimiazole and indole derivatives. ${ }^{6471}$ Notably, two residues, W397 and H428, that are critical for de novo initiation by $\mathrm{NS}^{6} \mathrm{~B}^{61}$ have side chains that chemically resemble the two classes of NNI that act at Site 1 (imidazole ring in H428 resembles benzimidazoles and indole ring in W397 resembles indoles). Substitutions of P495 to an Ala or a Leu also conferred resistance to benzimidazoles. ${ }^{64}$

The inability of the Site I NNI to inhibit NS5B involved in elongative RNA synthesis suggests that either the binding site is not available during elongation or that the $\Delta 1$ loop and thumb domain interactions are not required during elongative RNA synthesis. ${ }^{53,64,99,100}$

Plant-derived phytoestrogens have been shown to be effective against NS5B in biochemical assays and act as non-competitive inhibitors of NTPs and the template RNA. ${ }^{101}$ The mechanism of action is thought to be similar to that of benzimidazole compounds based on structure-activity relationship studies.

\section{Site 2}

Compounds based on the thiophene scaffold were originally identified by Shire Biochem Inc., as binding to NS5B in the thumb domain and inhibiting its activity. ${ }^{102}$ Compounds derived from the leads in this class are generally hydrophobic, consistent with the hydrophobic nature of the binding site that involves residues L419, M423, L474, and W528 (Figure 4B). In the genotype 1b NS5B, no gross change in the conformation of the enzyme was observed in the presence of the inhibitor, ${ }^{52,103}$ however, the genotype 2 a NS5B showed a pronounced change with the disruption of the helix $\mathrm{A}$ in the $\Delta 1$ loop that resulted in the formation of a $\beta$ sheet. ${ }^{51}$ Despite the availability of several crystal structures for the NS5B-inhibitor complex, ${ }^{51,52,102,103}$ a clear MOA remains to be elucidated for this class of inhibitors. This site is speculated to be involved with NS5B oligomerization, ${ }^{51,52,102}$ and inhibitor binding at this site may perturb function of the NS5B allosteric site. ${ }^{103}$ Pyranoindoles that putatively bind at Site 2 inhibit the transition between initiation and elongation stage of RNA synthesis. ${ }^{104}$

Mutations conferring resistance to Site 2 NNI include L419M and M423T. ${ }^{105}$ A minor population of drug-resistant clones carrying M423I and I482L were also observed in subgenomic replicons. When the mutations were introduced into WT replicons, all of them showed resistance to thiophene2-carboxylic acid derivatives. ${ }^{105}$ Although some inhibitors that act at Site 2 have exhibited low nanomolar $\mathrm{IC}_{50}$ values in biochemical assays, they generally had micromolar $\mathrm{IC}_{50}$ values in cell-based assays.

\section{Site 3}

Different classes of compounds have been described to bind to this site and inhibit NS5B (Figure 3). The first consists of derivatives of benzothiadiazines initially identified from the GlaxoSmithKline proprietary compound library ${ }^{106}$ with $0.5 \mu \mathrm{m} \mathrm{IC}{ }_{50}$ values in subgenomic replicons of genotype 1b. These compounds inhibit the initiation phase of RNA synthesis, but do not affect elongation or already assembled initiation complexes. ${ }^{37,107}$ Benzothiadiazines inhibited de novo initiation by WT $\Delta 21$ with $\mathrm{IC}_{50}$ values about 5-10-fold less than those for primer extension. ${ }^{37}$ Benzothiadiazines appear to act allosterically, as the inhibition is noncompetitive with GTP and RNA. ${ }^{37,106}$

Resistance mutations arising in HCV genotype $1 \mathrm{~b}$ replicons after exposure to benzothiadiazines include M414T, C451R, G558R, and H95R (Figure 4). ${ }^{37}$ Replicons with the M414T and H95R substitutions were unaffected for replication efficiency compared to the WT replicons, but replicons with the $\mathrm{C} 451 \mathrm{R}$ and G558R substitutions replicated at very low levels in absence of compounds and interestingly, showed a dose-dependent increase in replication. ${ }^{37}$ In biochemical RdRp assays, however, only M414T showed significant rescue from inhibition of RNA synthesis while H95R, C451R, and G558R did not.

Benzofuran-C3-carboxamide (HCV796) is a second class of drugs that bind at Site 3 and have a potent $\mathrm{EC}_{50}$ of 
$\sim 9 \mathrm{nM}$ in replicon cells. ${ }^{108}$ Its binding site overlaps, but is not identical to that of benzothiadiazines. HCV796 binds several residues in the 'primer-grip' site (residues 360-370) including C366. Also L314, C316, and M414 and mutations in these residues render NS5B resistant to HCV796 both in replicons and in biochemical enzymatic assays. ${ }^{109}$ HCV796 showed an excellent inhibitory profile in the chimeric mouse model ${ }^{108}$ and was approved by the FDA for phase II clinical trials. However, it showed severe hepatocellular toxicity in humans and its development has therefore been discontinued. ${ }^{110}$

A third class of Site 3 binders include 1,5-benzodiazepines which have $\mathrm{IC}_{50}$ values of $3-9 \mu \mathrm{M}$ in biochemical assays ${ }^{111}$ and $\mathrm{EC}_{50} \mathrm{~s}$ of $12-32 \mu \mathrm{M}$ in $\mathrm{HCV}$ replicon cells. Several of the NNI binding to all three sites described above are currently in clinical trials.

\section{Miscellaneous NS5B inhibitors}

Other classes of inhibitors based on aminorhodanine scaffold have been reported to inhibit NS5B by covalently modifying
C366 in the 'primer-grip' site (Figure 5). ${ }^{112}$ Dicarboxylic and diketo acid derivatives could bind in the active site of NS5B. ${ }^{113,114}$ These drugs act by chelating the active site magnesium ions as they act as pyrophosphate analogs. These compounds generally have poor cell permeability and may involve toxicity hence they have not been developed further.

Birroccio et $\mathrm{al}^{65}$ showed that a DNA aptamer selected to bind to NS5B by the SELEX approach was able to inhibit its activity. They further showed that the DNA aptamer bound to the exposed basic patch of the allosteric site on the thumb domain (Figure 1B). RNA aptamers have also been identified to bind NS5B and inhibit its activity in biochemical assays and in HCV infected cells. ${ }^{115}$ One aptamer, 27v, was competitive with RNA for binding to NS5B and prevented both initiation and elongation. A second aptamer, $127 \mathrm{v}$, was non-competitive with RNA and inhibited only pre-elongation events in RNA synthesis by NS5B. It is likely that $127 \mathrm{v}$ also binds to the allosteric site and inhibits NS5B in a mechanism similar to Site 1 NNI.

A

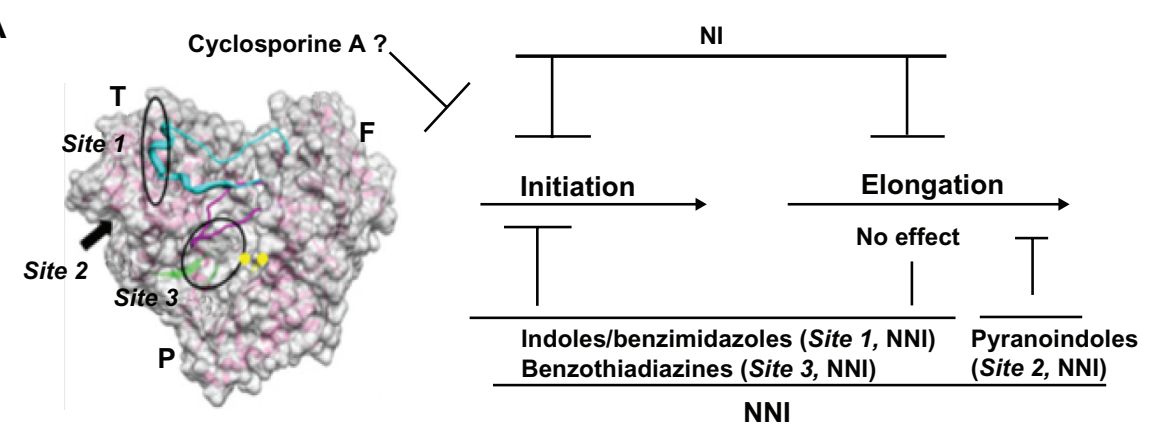

B

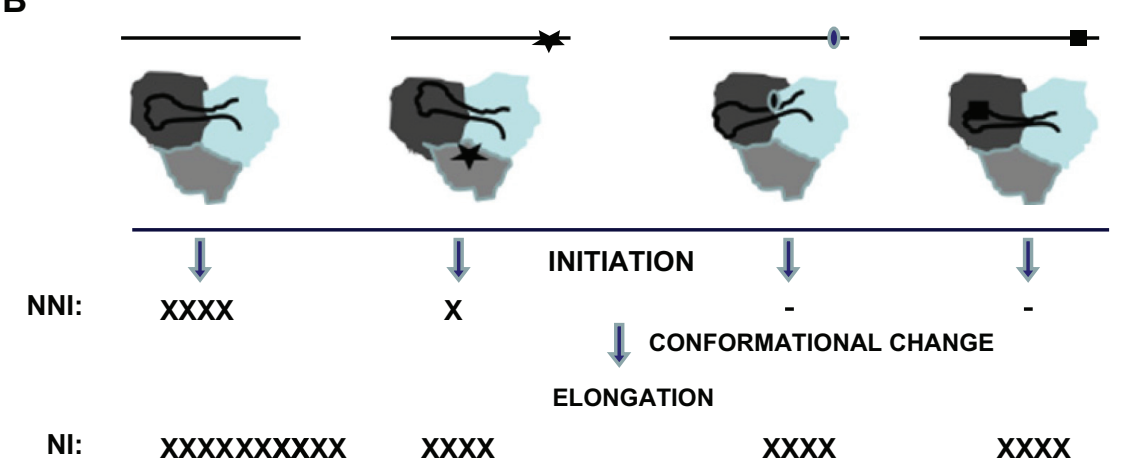

Figure 5 A summary of the effect of different $\mathrm{NI}$ and NNI on the mechanism of RNA synthesis by NS5B and the role of polymorphisms in therapeutic failures with NNI. A) NS5B PDB ID IQUV is shown as described in Figure 3. NI target the active site of NS5B and get incorporated into the nascent RNA and hence are effective in blocking both initiation and elongation events. NNI generally target the initiation of RNA synthesis by NS5B and do not affect elongation. However, Howe et al ${ }^{97}$ have reported that the pyranoindole class of drugs that bind to NNI Site 2 inhibit elongation, while synthesis of a 5 nt primer was not affected. Cyclosporine A prevents the interaction of cyclophilins with NS5B, however how cyclophilins manipulate NS5B's function is not clear. It is likely that cyclophilins help assemble productive initiation complexes by NS5B, and hence cyclosporine A may target initiation events in RNA synthesis. B) Presence of polymorphisms in the viral genome (black line) in the region encoding NS5B is shown as a star, an oval or a filled box. The resulting polymerases (the three domains are in different colors and the $\Delta \mathrm{I}$ loop is shown as a black line) have different conformations due to polymorphisms involving the drug binding sites and in other regions. NNI act during the initiation stage and their effect (denoted by Xs) are reduced in either polymerases with mutations in their binding sites or are difference in their conformations (number of Xs denotes the extent of inhibition). A conformational change occurs after initiation in NS5B and elongation ensues. NI that act as chain terminators target the elongating polymerase active site and get incorporated in the nascent RNA chain, and hence are not affected by the polymorphisms in NS5B and therefore are equally effective against NS5B of all genotypes. 


\section{Inhibitors that act indirectly on NS5B}

Cyclosporin A (CsA) and derivatives have been used as immunosuppressants in organ transplant patients. It was a surprise that CsA was found to be effective against $\mathrm{HCV}$ replication in subgenomic replicon cells. ${ }^{116}$ Given that CsA interacts with the class of peptidyl-prolyl isomerases named cyclophyllins, the latter were thought to be important for NS5B activity. In fact, cyclophylin B was found to increase RNA-binding by the HCV NS5B. ${ }^{116}$ However, most follow-up studies showed that CsA likely acts on cyclophylin A (CypA) to negatively affect $\mathrm{HCV}$ replication through NS5B as well as other HCV replication proteins. ${ }^{17,118}$ CypA may recruit NS5B to the replication complexes in the membranes ${ }^{118}$ and through its isomerase activity, cause a conformational change in NS5B that increases RNA binding. There may also be a cyclophilin A-independent recruitment of NS5B to replication complexes, as would be expected if cyclophilins acted to modify NS5B conformation. ${ }^{119}$ This activity may also act on other subunits of the HCV replicase like NS5A. ${ }^{120}$ NS5B mutations that render resistance to CsA include I11V and I432V which are within or are in very close proximity to the $\Delta 1$ loop. ${ }^{121}$ However, mutations like Q438R and E440G which are associated with the $\beta$ loop were also found to confer CsA resistance. ${ }^{121}$ CsA derivatives like NIM-811 and SCY-635 have generated much excitement in this novel class of NS5B inhibitors. ${ }^{122,123}$ A recent report points out an association between estrogen receptors and NS5B in HCV replicon carrying cells, and the anti-estrogen drug tamoxifen disrupted this association in a manner similar to that of CsA. ${ }^{124}$ It is presently unknown whether tamoxifen directly associates with NS5B. It is also of interest to note here that phytoestrogens were able to inhibit NS5B by a mechanism similar to that of Site 1 NNI. ${ }^{94}$

\section{NS5B inhibitors and RNA synthesis}

The inhibitory studies involving some of the compounds have also helped us gain a better understanding of the mechanism of RNA synthesis by NS5B. The indole/benzimidazole class of compounds binds to the 'finger-tip' region and since this region was thought to be critical to maintain the closed conformation of NS5B, it was thus quite revealing for the mechanism of RNA synthesis that they did not inhibit the phase corresponding to elongative RNA synthesis (Figure 5A). ${ }^{64,99,100,107}$ Subsequent analysis revealed that the closed conformation of NS5B is only needed for de novo initiation, but not elongative RNA synthesis. ${ }^{61}$ Site 1 compounds therefore bind at the 'finger-tip' region and prevent proper interaction between the fingers and thumb domains that is critical for initiation of RNA synthesis. ${ }^{53}$
Inhibitors that bind to Site 3 (particularly benzothiadiazines) also inhibited initiation by NS5B, but not the elongation stage of RNA synthesis despite acting at over $20 \AA$ from the 'finger-tip' regions. ${ }^{37}$ Site 3 compounds bind within the template channel, and none of the binding residues have been implicated in biochemical analysis to be specifically required for initiation. It is notable that $\mathrm{C} 451$ is a residue in the $\beta$ loop that is thought to be required for proper positioning of the template in the active site ${ }^{57}$ and a substitution to an arginine conferred resistance to benzothiadiazines. The benzofurans bind to the 'primer-grip' site and it is possible that this region may be involved with the optimal movement of the thumb and palm domains during initiation complex assembly. Biochemical evidence on the stage in RNA synthesis inhibited by the benzofuran drugs is not available. Site 3 binding compounds may prevent the formation of an overall closed structure in NS5B that will involve structures including the $\beta$ loop and the 'primer-grip site'.

The RNA synthesis assay used could have affected some of the interpretations of the results concerning the modes of RNA synthesis. ${ }^{37,64,99}$ While some studies used templates that could direct both de novo initiation and primer extension, others used heteropolymeric primer extension templates in their assays. ${ }^{64,99}$ We would like to emphasize the importance to distinguish initiation that occurred by a de novo mechanism or whether the first nucleotide was added to a preexisting primer. De novo initiation refers to the formation of a phosphodiester bond between the first and second nucleotide. Once the nascent RNA is extended to be $6-8 \mathrm{nt}$ in length, the polymerase ternary complex is thought to undergo some change to allow it to transition to a more processive elongative mode of RNA synthesis. ${ }^{90}$ In contrast, assays that examined whether the inhibitors affected the ability of NS5B to extend from an oligonucleotide-primed template will not assess whether de novo initiation was affected, but will assess pre-elongation events like productive RNA binding.

A lesson learned from the effects of the inhibitors is that the mode of RNA synthesis by HCV NS5B appears to be intimately linked to the conformation of the polymerase. As stated, the monomeric polymerase may exist in the closed conformation where there is extensive interaction between the finger and thumb domains mediated by structures such as the $\Delta 1$ loop, the $\beta$ loop, $\Delta 2$ loop, and the "primer-grip site' with different regions of the enzyme contributing to the overall closed structure that is thought to be the one involved in de novo initiation (Figure 1B). Alternatively, initiation may be through an oligomeric complex consisting of two or more RdRp subunits that result in conformational changes 
in each of the subunits that will favor initiation stages in RNA synthesis including productive RNA binding. Thus far, inhibitors that bind Site 1 and Site 3 appear to interfere with the closed NS5B conformation as per crystallographic evidence. Interestingly, they may perturb this conformation and then prevent proper initiation of RNA synthesis while allowing the polymerase to retain the ability to extend from a primed template. As oligomeric contacts between NS5B subunits are thought to be mediated by ionic interactions, ${ }^{72}$ it may be a challenge to obtain suitable drugs with appreciable pharmacokinetic properties that will target the NS5B oligomerization step.

The role of cyclophilins in RNA synthesis by NS5B is not as clear, although they are needed to increase RNA binding by NS5B. ${ }^{116,121}$ It is possible that the peptidyl-prolyl isomerase activity of cyclophilins could act on the proline residues in NS5B to change the conformation of the monomer molecule and/or higher order structures of NS5B and assist in productive binding to RNA, therefore influencing initiation rather than elongation RNA synthesis (Figure 5A). Notably, I432V and $\mathrm{I} 11 \mathrm{~V}$ conferred increased affinity for RNA binding, in support of the idea that cyclophyllin A is affecting the NS5B interaction with RNA.

\section{HCV genotypic variation in inhibitor response}

$\mathrm{HCV}$ exists as six known genotypes and a number of subtypes. Within the infected individual, significant differences in the viral sequences are commonly encountered, demonstrating that each subtype is a quasispecies. ${ }^{125}$ NI that inhibit NS5B by effecting chain termination will do so primarily by targeting the elongation stage of RNA synthesis. In contrast, the majority of NNI target the conformation of the polymerase to prevent initiation. With these two mechanisms in mind, it is noteworthy that NI tend to be effective at approximately comparable levels among all HCV genotypes while NNI tend to exhibit genotypic-specific differences in responses. ${ }^{76,125-129}$ In fact, significant differences in response to NNI have been noted within different viral sequences isolated from the same individual. ${ }^{125}$ This suggests that different viral isolates have either mechanistic differences in the initiation complex assembly or variations in the binding pockets for NNIs.

$\mathrm{Gu}$ et al have shown differences in oligomeric properties and enzymatic activities in NS5B from genotype 1a and $1 b .{ }^{73}$ It is likely that differences exist in the binding constants for NS5B oligomerization across genotypes to affect the efficiency of initiation of RNA synthesis. Pauwels et al ${ }^{128}$ used biochemical assays to show that among the NNIs, benzimidazoles (Site 1) did not show much variation in $\mathrm{IC}_{50}$ values across genotypes except that they were about 100-fold higher for genotype $2 \mathrm{a}$ and $2 \mathrm{~b}$. Site 2 and Site 3 inhibitors showed significant genotypic variation in responses, consistent with an altered binding site being responsible for the observed differences. For example, a polar residue at position 414 was not tolerated by the 2 a NS5B to bind benzothiadiazines while a Q414M mutation partially restored the inhibition. In a similar observation 1,5-benzodiazipines were effective against only genotype $1 \mathrm{a}$ and 1b NS5B while Q414M mutation led to only a partial inhibition of the genotype 2a NS5B. ${ }^{111}$

Ludmerer et al amplified the NS5B sequences from patient sera, cloned the cDNAs into a genotype $1 \mathrm{~b}$ con 1 background and assessed them for sensitivity to different NI and NNI. ${ }^{25}$ Interestingly, more than $90 \%$ of these sequences are split into two major groups of A218, C316, and Q464 (ACQ) which appear in con1, and S218, N316, and E464 which appear in BK isolate. ${ }^{125}$ While NI affected all of the replicons, differences existed in the responses to NNI. For a patient treated with benzimidazoles, viruses with changes in NS5B sequences that responded with a difference of almost 20-fold to the drug were found. This difference was more pronounced with the patients with genotype $1 \mathrm{~b}$ infection than with genotype $1 \mathrm{a}$ infection. Furthermore, benzothiadiazines were not effective on isolates from a patient with genotype $1 \mathrm{~b}$ infection at three times the $\mathrm{EC}_{50}$ value $\left(\mathrm{EC}_{50}\right.$ was determined for a consensus con1 NS5B). The response to thiophenes was somewhat uniform among different isolates in the same study.

Herlihy et $\mathrm{al}^{127}$ found a variation of $0 \%-7 \%$ at the amino acid level in the NS5B sequences from the viral population present in each patient. In this study, replicons were constructed with a con 1 background containing consensus NS5B sequences from non-genotype 1 viruses obtained from patient sera and then evaluated for their response to different NI and NNI. While NM107 (2'-C-methylcytidine) and a NS3 protease inhibitor elicited a similar response in chimeric replicons containing NS5B from different genotypes, differences were clear when NNI were tested. Benzimidazoles elicited a similar response in genotypes $1 \mathrm{~b}, 3 \mathrm{a}, 4 \mathrm{a}$, and $5 \mathrm{a}$, but up to a 30 -fold reduction in response from genotype $2 \mathrm{a}$ and $2 \mathrm{~b}$ was noted. Thiophenes had an 8 -fold reduction in response from genotype $5 \mathrm{a}$ compared to $1 \mathrm{~b}$, while genotypes $2 \mathrm{~b}, 3 \mathrm{a}$, and $4 \mathrm{a}$ did not have any significant response. Benzothiadiazines did not result in significant response from any of the genotypes at concentrations that were inhibitory to genotype $1 \mathrm{~b}$ replicons. Interestingly, benzofuran (HCV796) that binds to Site 3 had a comparable response from all genotype 
1 and non-genotype 1 NS5B-containing replicons. Notably, the $\mathrm{C} 316 \mathrm{Y}$ mutation that confers resistance to HCV-796 is frequently present in viruses resistant to combinations of NS5B and NS3 inhibitor. ${ }^{104}$

These results collectively demonstrate that the viral quasispecies, as well differences between viral genotypes, can be major factors in therapeutic failures. NNI target the initiation complex formation in NS5B, and therefore are dependent on strict conservation of their binding sites for binding and inhibition (Figure 5B). Since NS5B lacks proofreading activity and readily incorporates mutations in the genome, polymorphisms are common in the NNI binding sites. ${ }^{128}$ In contrast, NI compete for binding with the NTPs, which should make them effective against all of the HCV genotypes at similar levels.

Changes in the viral genome as well as the genetics of the infected individual could affect the response to the ribavirin-interferon combination therapy that is currently the only approved therapy for HCV infections. ${ }^{7,130}$ The "nonresponders' to this combination therapy interestingly have viruses that have about 3-fold more hydrophobic sequences in the viral proteins along with a pattern of co-varying residues. ${ }^{131}$ These predictions remain to be tested in more defined systems. Clearly, more genomic analysis as well as studies in chimpanzees, or mice transplanted with human livers, ${ }^{17}$ will be needed in order to improve the strategies for antiviral development against HCV.

\section{Variations within the HCV NS5B sequence and potential impact on effects of NNI}

The available data on the emergence of resistant mutations to various inhibitors of NS5B described above prompted us to examine the natural prevalence of these mutations in 480 $\mathrm{HCV}$ isolate sequences, which comprised $465 \mathrm{HCV}$ isolate sequences deposited in the HCV database ${ }^{132}$ and 15 genotype 6a sequences extracted from NCBI. ${ }^{133}$ All the sequences used were complete genome sequences and were divided into the following genotypes further analysis: genotypes 1a, 1b, 1c, 2 , $3,4,5 a$, and 6 (Table 1). In summary, genotypes $1 \mathrm{a}$ and $1 \mathrm{~b}$ contained isolates with mutations in the residues that are putatively

Table I The presence of potential resistant mutations in the NS5B proteins of HCV from different genotype

\begin{tabular}{|c|c|c|c|c|c|c|c|c|c|}
\hline \multirow[t]{2}{*}{ Compound } & \multirow{2}{*}{$\begin{array}{l}\text { Resistant } \\
\text { Mutation }\end{array}$} & \multicolumn{8}{|c|}{ HCV genotype (number of NS5B sequences analyzed) } \\
\hline & & Ia $(166)^{*}$ & Ib (232) & Ic (3) & $2^{\#}(17)$ & $3^{\#}(7)$ & $4^{\#}(8)$ & $5 a(2)$ & $6^{\#}(45)$ \\
\hline \multirow{3}{*}{$\begin{array}{l}\text { 2' ribose modified } \\
\text { nucleoside analogs }\end{array}$} & S282T-Ib & $S / R(I)^{\wedge}$ & & & & & $S / R(I)$ & & \\
\hline & S96T-Ib & & & & & & & & \\
\hline & NI42T-Ib & & N/S (23); N/T (I) & & & & & & \\
\hline Ribavirin & Y4I5F-la & Y/F (2) & Y/F (3) & & & Y/F (2) & & & Y/F (I) \\
\hline Benzimidazoles & P495A/L-Ib & & & & & & & & \\
\hline \multirow{4}{*}{$\begin{array}{l}\text { Thiophene-2- } \\
\text { carboxylic acid }\end{array}$} & L4I9M-Ib & & $\mathrm{L} / \mathrm{l}(2)$ & & $\mathrm{L} / \mathrm{V}(3)$ & $\mathrm{L} / \mathrm{l}(7)$ & L/l (8) & & L/I (45) \\
\hline & M423T/I/V-Ib & M/A (I); & & & & & & $M / I(2)$ & \\
\hline & & $M / I(I)$ & & & & & & & \\
\hline & I482L-Ib & $\mathrm{I} / \mathrm{L}(\mathrm{I})$ & & & & I/L (7) & $I / L(8)$ & & I/L (45) \\
\hline \multirow[t]{8}{*}{ Benzothiadiazine } & M4I4T-Ib & $M / V(I)$ & $M / I(I)$ & & $M / Q(17)$ & & $M / I(2)$; & & \\
\hline & & & & & & & $M / V(6)$ & & \\
\hline & C45IR-Ib & $C / Y(I)$ & C/R (I); C/N (I); & $\mathrm{C} / \mathrm{V}(2)$ & $\mathrm{C} / \mathrm{V}(17)$ & $\mathrm{C} / \mathrm{T}(\mathrm{I})$ & $\mathrm{C} / \mathrm{T}(8)$ & $\mathrm{C} / \mathrm{V}(2)$ & $\mathrm{C} / \mathrm{T}(45)$ \\
\hline & & $\mathrm{C} / \mathrm{V}(\mathrm{I})$ & C/H (3); C/I (7); & $\mathrm{C} / \mathrm{T}(\mathrm{I})$ & & $\mathrm{C} / \mathrm{V}(6)$ & & & \\
\hline & & & $\mathrm{C} / \mathrm{S}$ (I); C/T (22); & & & & & & \\
\hline & & & C/Y (9); C/V (2) & & & & & & \\
\hline & G558R-Ib & & & & & & $\mathrm{G} / \mathrm{E}(\mathrm{I})$ & & \\
\hline & H95R-Ib & & $\mathrm{H} / \mathrm{L}(\mathrm{I})$ & & & & & & H/R (I) \\
\hline \multirow[t]{3}{*}{ Indole-N-acetamides } & L392I-Ib & L/F (5) & L/F (4); L/I (5) & & L/I (I3) & & & & L/I (I) \\
\hline & V494A-Ib & & & & VIA (I7) & V/C (4); V/I (3) & & & VIA (29); \\
\hline & & & & & & & & & $\mathrm{V} / \mathrm{M}(\mathrm{I})$ \\
\hline HCV-796 & C3I6Y-Ib & & $\mathrm{C} / \mathrm{N}(93) ; \mathrm{C} / \mathrm{Y}(\mathrm{I})$ & & & & & & \\
\hline \multirow[t]{2}{*}{ Dihydroxypyrimidines } & GI52E-Ib & P/A (2) & P/A (4); P/S (I) & & P/A (I3) & P/A (I); P/R (I) & P/A (I) & & $\mathrm{P} / \mathrm{S}(\mathrm{I})$ \\
\hline & PI56L-Ib & & & & & & & & \\
\hline
\end{tabular}

"The number of sequences analyzed in each genotype.^The numbers in parentheses indicate the number of the mutation identified in the data set. Grids left blank had no mutation identified in the analysis. The original residue from the typical HCV sequence is followed with the residue identified in one letter amino acid code. Mutations identified in red are identical or highly similar to those characterized to be resistant to the compounds. $2^{\#}$ includes genotype $2 \mathrm{a}, 2 \mathrm{~b}, 2 \mathrm{c}, 2 \mathrm{k}$; $3^{\#}$ includes genotype $3 \mathrm{a}$, $3 \mathrm{~b}, 3 \mathrm{k}$; $4^{\#}$ includes genotype $4 \mathrm{a}, 4 \mathrm{~d} ; 6^{\#}$ includes genotype 6a-6q, 6t and one unassigned subtype. 
involved with NNI that bind at Site 2 and Site 3 . The residues that bind to Site 2 NNI, particularly L419, had polymorphisms in several HCV genotypes. The I482L mutation in Site 2 NNI was present in genotypes 1a, 3, 4, and 6. Residue C451 that is involved with binding to Site 3 NNI also had polymorphisms all of the HCV genotypes. Mutation Y415F that conferred resistance to ribavirin was characteristically found in all the genotypes except genotypes 1c, 2, and 5a. Mutations that contributed to resistance to Indole-N-acetamides, L392I and V494A, were in isolates from $1 \mathrm{~b}, 2$, and $6 .{ }^{134}$ Interestingly, mutation $\mathrm{C} 316 \mathrm{Y}$ that was commonly found in strains with resistance to $\mathrm{HCV}-796$ was only found in genotype $1 \mathrm{~b}$ and at a low frequency. ${ }^{135} \mathrm{P} 156$ that helped to confer resistance to the pyrophosphate mimic, dihydroxypyrimidines, was commonly found to be changed, although not to the leucine reported by Powdrill et al ${ }^{85}$ However, the G152 residue did not vary across the genotypes. In brief, this analysis reveals that sequence variations that are already present in various HCV genotypes could significantly impact antiviral therapies.

\section{Summary}

This review summarized the structural and functional aspects of NS5B and how they impact both RNA synthesis and the development of inhibitors. Clearly much work remains before control of HCV infection is possible. It is also increasingly clear that any inhibitors that target NS5B must be used in combination with other $\mathrm{HCV}$ and/or cellular targets to affect the outcome of persistent HCV infection.

\section{Acknowledgment}

We would like to acknowledge several reports that have contributed to the mechanism of RNA synthesis by RdRps that may have not been cited in this review. We thank Laura Kao for editing this manuscript.

\section{Disclosure}

The authors report no conflicts of interest in this work.

\section{References}

1. Orlando R, Lirussi F. Hepatitis C virus infection: sexual or non-sexual transmission between spouses? A case report and review of the literature. Infection. 2007;35(6):465-468.

2. El-Serag HB. Hepatocellular carcinoma: recent trends in the United States. Gastroenterology. 2004;127(5 Suppl 1):S27-S34.

3. Micallef JM, Kaldor JM, Dore GJ. Spontaneous viral clearance following acute hepatitis $\mathrm{C}$ infection: a systematic review of longitudinal studies. J Viral Hepat. 2006;13(1):34-41.

4. Lai ME, Mazzoleni AP, Argiolu F, et al. Hepatitis C virus in multiple episodes of acute hepatitis in polytransfused thalassaemic children. Lancet. 1994;343(8894):388-390.

5. Wasley A, Alter MJ. Epidemiology of hepatitis C: geographic differences and temporal trends. Semin Liver Dis. 2000;20(1):1-16.
6. Choo QL, Kuo G, Weiner AJ, Overby LR, Bradley DW, Houghton M. Isolation of a cDNA clone derived from a blood-borne non-A, non-B viral hepatitis genome. Science. 1989;244(4902):359-362.

7. Shimakami T, Lanford RE, Lemon SM. Hepatitis C: recent successes and continuing challenges in the development of improved treatment modalities. Curr Opin Pharmacol. 2009;9(5):537-544.

8. Diviney S, Tuplin A, Struthers M, et al. A hepatitis $\mathrm{C}$ virus cis-acting replication element forms a long-range RNA-RNA interaction with upstream RNA sequences in NS5B. J Virol. 2008;82(18):9008-9022.

9. Shi ST, Lee KJ, Aizaki H, Hwang SB, Lai MM. Hepatitis C virus RNA replication occurs on a detergent-resistant membrane that cofractionates with caveolin-2. J Virol. 2003;77(7):4160-4168.

10. Moradpour D, Penin F, Rice CM. Replication of hepatitis C virus. Nat Rev Microbiol. 2007;5(6):453-463.

11. McLauchlan J. Hepatitis C virus: viral proteins on the move. Biochem Soc Trans. 2009;37(Pt 5):986-990.

12. Gale M Jr, Foy EM. Evasion of intracellular host defence by hepatitis C virus. Nature 2005;436(7053):939-945.

13. Krekulova L, Rehak V, Riley LW. Structure and functions of hepatitis C virus proteins: 15 years after. Folia Microbiol (Praha). 2006;51(6):665-680.

14. McGivern DR, Lemon SM. Tumor suppressors, chromosomal instability, and hepatitis C virus-associated liver cancer. Annu Rev Pathol. 2009;4:399-415.

15. Kolykhalov AA, Feinstone SM, Rice CM. Identification of a highly conserved sequence element at the 3 ' terminus of hepatitis $\mathrm{C}$ virus genome RNA. J Virol. 1996;70(6):3363-3371.

16. Tellinghuisen TL, Evans MJ, von Hahn T, You S, Rice CM. Studying hepatitis C virus: making the best of a bad virus. J Virol. 2007; 81(17):8853-8867.

17. Mercer DF, Schiller DE, Elliott JF, et al. Hepatitis C virus replication in mice with chimeric human livers. Nat Med. 2001;7(8):927-933.

18. Amako Y, Tsukiyama-Kohara K, Katsume A, et al. Pathogenesis of hepatitis C virus infection in Tupaia belangeri. J Virol. 2010; 84(1):303-311.

19. Lohmann V, Korner F, Koch J, Herian U, Theilmann L, Bartenschlager R. Replication of subgenomic hepatitis $\mathrm{C}$ virus RNAs in a hepatoma cell line. Science. 1999;285(5424):110-113.

20. Sumpter R, Loo YM, Foy E, et al. Regulating intracellular antiviral defense and permissiveness to hepatitis $\mathrm{C}$ virus RNA replication through a cellular RNA helicase, RIG-I. J Virol. 2005;79(5):2689-2699.

21. Blight KJ, McKeating JA, Rice CM. Highly permissive cell lines for subgenomic and genomic hepatitis C virus RNA replication. J Virol. 2002;76(24):13001-13014.

22. Blight KJ, McKeating JA, Marcotrigiano J, Rice CM. Efficient replication of hepatitis $\mathrm{C}$ virus genotype 1a RNAs in cell culture. J Virol. 2003;77(5):3181-3190.

23. Krieger N, Lohmann V, Bartenschlager R. Enhancement of hepatitis C virus RNA replication by cell culture-adaptive mutations. J Virol. 2001;75(10):4614-4624.

24. Pietschmann T, Lohmann V, Kaul A, et al. Persistent and transient replication of full-length hepatitis $\mathrm{C}$ virus genomes in cell culture. J Virol. 2002;76(8):4008-4021.

25. Wakita T, Pietschmann T, Kato T, et al. Production of infectious hepatitis $\mathrm{C}$ virus in tissue culture from a cloned viral genome. Nat Med. 2005;11(7):791-796.

26. Kato T, Furusaka A, Miyamoto M, et al. Sequence analysis of hepatitis $\mathrm{C}$ virus isolated from a fulminant hepatitis patient. J Med Virol. 2001;64(3):334-339.

27. Kato T, Choi Y, Elmowalid G, et al. Hepatitis C virus JFH-1 strain infection in chimpanzees is associated with low pathogenicity and emergence of an adaptive mutation. Hepatology. 2008;48(3): 732-740.

28. Choi KH, Rossmann MG. RNA-dependent RNA polymerases from Flaviviridae. Curr Opin Struct Biol. 2009;19(6):746-751.

29. Steitz TA. DNA polymerases: structural diversity and common mechanisms. J Biol Chem. 1999;274(25):17395-17398. 
30. van Dijk AA, Makeyev EV, Bamford DH. Initiation of viral RNA-dependent RNA polymerization. J Gen Virol. 2004;85(Pt 5): 1077-1093.

31. Tomei L, Vitale RL, Incitti I, et al. Biochemical characterization of a hepatitis $\mathrm{C}$ virus RNA-dependent RNA polymerase mutant lacking the C-terminal hydrophobic sequence. J Gen Virol. 2000;81(Pt 3): 759-767.

32. Moradpour D, Brass V, Bieck E, et al. Membrane association of the RNA-dependent RNA polymerase is essential for hepatitis $\mathrm{C}$ virus RNA replication. J Virol. 2004;78(23):13278-13284.

33. Bressanelli S, Tomei L, Rey FA, De Francesco R. Structural analysis of the hepatitis $\mathrm{C}$ virus RNA polymerase in complex with ribonucleotides. J Virol. 2002;76(7):3482-3492.

34. Ranjith-Kumar CT, Gajewski J, Gutshall L, Maley D, Sarisky RT, Kao CC. Terminal nucleotidyl transferase activity of recombinant Flaviviridae RNA-dependent RNA polymerases: implication for viral RNA synthesis. J Virol. 2001;75(18):8615-8623.

35. Ranjith-Kumar CT, Gutshall L, Kim MJ, Sarisky RT, Kao CC. Requirements for de novo initiation of RNA synthesis by recombinan flaviviral RNA-dependent RNA polymerases. J Virol. 2002;76(24): 12526-12536.

36. Ranjith-Kumar CT, Gutshall L, Sarisky RT, Kao CC. Multiple interactions within the hepatitis $\mathrm{C}$ virus RNA polymerase repress primerdependent RNA synthesis. $J$ Mol Biol. 2003;330(4):675-685.

37. Tomei L, Altamura S, Bartholomew L, et al. Characterization of the inhibition of hepatitis C virus RNA replication by nonnucleosides. J Virol. 2004;78(2):938-946.

38. Wang QM, Johnson RB, Chen D, et al. Expression and purification of untagged full-length HCV NS5B RNA-dependent RNA polymerase Protein Expr Purif. 2004;35(2):304-312.

39. Bressanelli S, Tomei L, Roussel A, et al. Crystal structure of the RNAdependent RNA polymerase of hepatitis C virus. Proc Natl Acad Sci U S A. 1999;96(23):13034-13039.

40. Behrens SE, Tomei L, De Francesco R. Identification and properties of the RNA-dependent RNA polymerase of hepatitis C virus. EMBO J. 1996;15(1):12-22.

41. Lohmann V, Korner F, Herian U, Bartenschlager R. Biochemical properties of hepatitis $\mathrm{C}$ virus NS5B RNA-dependent RNA polymerase and identification of amino acid sequence motifs essential for enzymatic activity. J Virol. 1997;71(11):8416-8428.

42. Kao CC, Del Vecchio AM, Zhong W. De novo initiation of RNA synthesis by a recombinant flaviviridae RNA-dependent RNA polymerase. Virology. 1999;253(1):1-7.

43. Kao CC, Yang X, Kline A, Wang QM, Barket D, Heinz BA. Template requirements for RNA synthesis by a recombinant hepatitis $\mathrm{C}$ virus RNAdependent RNA polymerase. J Virol. 2000;74(23):11121-11128.

44. Luo G, Hamatake RK, Mathis DM, et al. De novo initiation of RNA synthesis by the RNA-dependent RNA polymerase (NS5B) of hepatitis C virus. JVirol. 2000;74(2):851-863.

45. Oh JW, Ito T, Lai MM. A recombinant hepatitis C virus RNAdependent RNA polymerase capable of copying the full-length viral RNA. J Virol. 1999;73(9):7694-7702.

46. Zhong W, Uss AS, Ferrari E, Lau JY, Hong Z. De novo initiation of RNA synthesis by hepatitis $\mathrm{C}$ virus nonstructural protein $5 \mathrm{~B}$ polymerase. J Virol. 2000;74(4):2017-2022.

47. Sun XL, Johnson RB, Hockman MA, Wang QM. De novo RNA synthesis catalyzed by HCV RNA-dependent RNA polymerase. Biochem Biophys Res Commun. 2000;268(3):798-803.

48. Lohmann V, Overton H, Bartenschlager R. Selective stimulation of hepatitis $\mathrm{C}$ virus and pestivirus NS5B RNA polymerase activity by GTP. J Biol Chem. 1999;274(16):10807-10815.

49. Lesburg CA, Cable MB, Ferrari E, Hong Z, Mannarino AF, Weber PC. Crystal structure of the RNA-dependent RNA polymerase from hepatitis C virus reveals a fully encircled active site. Nat Struct Biol. 1999;6(10):937-943.

50. Ago H, Adachi T, Yoshida A, et al. Crystal structure of the RNA-dependent RNA polymerase of hepatitis C virus. Structure. 1999;7(11):1417-1426.
51. Biswal BK, Cherney MM, Wang M, et al. Crystal structures of the RNA-dependent RNA polymerase genotype 2a of hepatitis C virus reveal two conformations and suggest mechanisms of inhibition by nonnucleoside inhibitors. J Biol Chem. 2005;280(18):18202-18210.

52. Biswal BK, Wang M, Cherney MM, et al. Non-nucleoside inhibitors binding to hepatitis C virus NS5B polymerase reveal a novel mechanism of inhibition. $J$ Mol Biol. 2006;361(1):33-45.

53. Di Marco S, Volpari C, Tomei L, et al. Interdomain communication in hepatitis $\mathrm{C}$ virus polymerase abolished by small molecule inhibitors bound to a novel allosteric site. J Biol Chem. 2005;280(33):29765-29770.

54. O'Farrell D, Trowbridge R, Rowlands D, Jager J. Substrate complexes of hepatitis C virus RNA polymerase (HC-J4): structural evidence for nucleotide import and de-novo initiation. $J \mathrm{Mol} \mathrm{Biol}$. 2003;326(4):1025-1035

55. Simister P, Schmitt M, Geitmann M, et al. Structural and functional analysis of hepatitis $\mathrm{C}$ virus strain JFH1 polymerase. $J$ Virol. 2009;83(22):11926-11939.

56. Choi KH, Groarke JM, Young DC, et al. The structure of the RNAdependent RNA polymerase from bovine viral diarrhea virus establishes the role of GTP in de novo initiation. Proc Natl Acad Sci U SA. 2004;101(13):4425-4430.

57. Hong Z, Cameron CE, Walker MP, et al. A novel mechanism to ensure terminal initiation by hepatitis C virus NS5B polymerase. Virology. 2001;285(1):6-11.

58. Butcher SJ, Grimes JM, Makeyev EV, Bamford DH, Stuart DI A mechanism for initiating RNA-dependent RNA polymerization. Nature. 2001;410(6825):235-240.

59. Labonte P, Axelrod V, Agarwal A, Aulabaugh A, Amin A, Mak P Modulation of hepatitis C virus RNA-dependent RNA polymerase activity by structure-based site-directed mutagenesis. J Biol Chem. 2002;277(41):38838-38846.

60. Doublie S, Sawaya MR, Ellenberger T. An open and closed case for all polymerases. Structure. 1999;7(2):R31-R35.

61. Chinnaswamy S, Yarbrough I, Palaninathan S, et al. A locking mechanism regulates RNA synthesis and host protein interaction by the hepatitis C virus polymerase. J Biol Chem. 2008;283(29):20535-20546.

62. Cai Z, Yi M, Zhang C, Luo G. Mutagenesis analysis of the rGTPspecific binding site of hepatitis $\mathrm{C}$ virus RNA-dependent RNA polymerase. J Virol. 2005;79(18):11607-11617.

63. Qin W, Luo H, Nomura T, et al. Oligomeric interaction of hepatitis C virus NS5B is critical for catalytic activity of RNA-dependent RNA polymerase. J Biol Chem. 1999;277:2132-2137.

64. Tomei L, Altamura S, Bartholomew L, et al. Mechanism of action and antiviral activity of benzimidazole-based allosteric inhibitors of the hepatitis C virus RNA-dependent RNA polymerase. $J$ Virol. 2003;77(24):13225-13231.

65. Biroccio A, Hamm J, Incitti I, De Francesco R, Tomei L. Selection of RNA aptamers that are specific and high-affinity ligands of the hepatitis $\mathrm{C}$ virus RNA-dependent RNA polymerase. J Virol. 2002;76(8):3688-3696.

66. Rubach JK, Wasik BR, Rupp JC, Kuhn RJ, Hardy RW, Smith JL. Characterization of purified Sindbis virus nsP4 RNA-dependent RNA polymerase activity in vitro. Virology. 2009;384(1):201-208.

67. Deval J, Powdrill MH, D'Abramo CM, Cellai L, Gotte M. Pyrophosphorylytic excision of nonobligate chain terminators by hepatitis $\mathrm{C}$ virus NS5B polymerase. Antimicrob Agents Chemother. 2007; 51(8): 2920-2928

68. Laurila MR, Makeyev EV, Bamford DH. Bacteriophage phi 6 RNAdependent RNA polymerase: molecular details of initiating nucleic acid synthesis without primer. J Biol Chem. 2002;277(19):17117-17124.

69. Ranjith-Kumar CaKC. Recombinant viral RdRps can initiate RNA synthesis from circular templates. RNA. 2006;12:303-312.

70. Kaul A, Stauffer S, Berger C, et al. Essential role of cyclophilin A for hepatitis $\mathrm{C}$ virus replication and virus production and possible link to polyprotein cleavage kinetics. PLoS Pathog. 2009;5(8):e1000546.

71. Ferrari E, He Z, Palermo RE, Huang HC. Hepatitis C virus NS5B polymerase exhibits distinct nucleotide requirements for initiation and elongation. J Biol Chem. 2008;283(49):33893-33901. 
72. Ackermann M, Padmanabhan R. De novo synthesis of RNA by the dengue virus RNA-dependent RNA polymerase exhibits temperature dependence at the initiation but not elongation phase. J Biol Chem. 2001;276(43):39926-39937.

73. Wang QM, Hockman MA, Staschke K, et al. Oligomerization and cooperative RNA synthesis activity of hepatitis C virus RNAdependent RNA polymerase. J Virol. 2002;76(8):3865-3872.

74. Gu B, Gutshall LL, Maley D, et al. Mapping cooperative activity of the hepatitis $\mathrm{C}$ virus RNA-dependent RNA polymerase using genotype 1a-1b chimeras. Biochem Biophys Res Commun. 2004;313(2): 343-350.

75. Hobson SD, Rosenblum ES, Richards OC, Richmond K, Kirkegaard K, Schultz SC. Oligomeric structures of poliovirus polymerase are important for function. EMBO J. 2001;20(5):1153-1163.

76. Hogbom M, Jager K, Robel I, Unge T, Rohayem J. The active form of the norovirus RNA-dependent RNA polymerase is a homodimer with cooperative activity. J Gen Virol. 2009;90(Pt 2):281-291.

77. Burton JR Jr, Everson GT. HCV NS5B polymerase inhibitors. Clin Liver Dis. 2009;13(3):453-465.

78. Carroll SS, Tomassini JE, Bosserman M, et al. Inhibition of hepatitis C virus RNA replication by 2'-modified nucleoside analogs. J Biol Chem. 2003;278(14):11979-11984

79. Migliaccio G, Tomassini JE, Carroll SS, et al. Characterization of resistance to non-obligate chain-terminating ribonucleoside analogs that inhibit hepatitis $\mathrm{C}$ virus replication in vitro. J Biol Chem. 2003;278(49):49164-49170.

80. Olsen DB, Eldrup AB, Bartholomew L, et al. A 7-deaza-adenosine analog is a potent and selective inhibitor of hepatitis $\mathrm{C}$ virus replication with excellent pharmacokinetic properties. Antimicrob Agents Chemother. 2004;48(10):3944-3953.

81. Cameron C, Gotte M, Raney KD, editor. Viral Genome Replication. New York: Springer; 2009.

82. Stuyver LJ, McBrayer TR, Tharnish PM, et al. Inhibition of hepatitis C replicon RNA synthesis by beta-D-2'-deoxy-2'-fluoro-2'-Cmethylcytidine: a specific inhibitor of hepatitis $\mathrm{C}$ virus replication. Antivir Chem Chemother. 2006;17(2):79-87.

83. Shim J, Larson G, Lai V, Naim S, Wu JZ. Canonical 3'-deoxyribonucleotides as a chain terminator for HCV NS5B RNA-dependent RNA polymerase. Antiviral Res. 2003;58(3):243-251.

84. Klumpp K, Leveque V, Le Pogam S, et al. The novel nucleoside analog R1479 (4'-azidocytidine) is a potent inhibitor of NS5B-dependent RNA synthesis and hepatitis $\mathrm{C}$ virus replication in cell culture. J Biol Chem. 2006;281(7):3793-3799.

85. Powdrill MH, Deval J, Narjes F, DeFrancesco RD, Gotte M. Mechanism of hepatitic $\mathrm{C}$ virus polymerase inhibitio with dihydroxypyrimidines. Antimicro Agents Chemother. 2010;54(3):977-983.

86. Tomei L, Altamura S, Paonessa G, De Francesco R, Gotte M. HCV antiviral resistance: the impact of in vitro studies on the development of antiviral agents targeting the viral NS5B polymerase. Antivir Chem Chemother. 2005;16(4):225-245.

87. Feld JJ, Hoofnagle JH. Mechanism of action of interferon and ribavirin in treatment of hepatitis C. Nature. 2005;436(7053):967-972.

88. Young $\mathrm{KC}$, Lindsay $\mathrm{KL}$, Lee $\mathrm{KJ}$, et al. Identification of a ribavirinresistant NS5B mutation of hepatitis $\mathrm{C}$ virus during ribavirin monotherapy. Hepatology. 2003;38(4):869-878.

89. Le Pogam S, Jiang WR, Leveque V, et al. In vitro selected Con1 subgenomic replicons resistant to 2'-C-methyl-cytidine or to R1479 show lack of cross resistance. Virology. 2006;351(2):349-359.

90. Kao CC, Singh P, Ecker DJ. De novo initiation of viral RNA-dependent RNA synthesis. Virology. 2001;287(2):251-260.

91. Ranjith-Kumar CT, Sarisky RT, Gutshall L, Thomson M, Kao CC. De novo initiation pocket mutations have multiple effects on hepatitis $\mathrm{C}$ virus RNA-dependent RNA polymerase activities. $J$ Virol. 2004;78(22):12207-12217.

92. Zhong W, An H, Barawkar D, Hong Z. Dinucleotide analogues as novel inhibitors of RNA-dependent RNA polymerase of hepatitis C Virus. Antimicrob Agents Chemother. 2003;47(8):2674-2681.
93. Ichikawa E, Kato K. Sugar-modified nucleosides in the past 10 years, a review. Curr Med Chem. 2001;8(4):385-423.

94. Perrone P, Luoni GM, Kelleher MR, et al. Application of the phosphoramidite ProTide approach to 4' azidouridine confers sub-micromolar potency versus hepatitis $\mathrm{C}$ virus on an inactive nucleoside. $\mathrm{J} \mathrm{Med}$ Chem. 2007;50:1840-1849.

95. McGuigan C, Daverio F, Najera I, Martin JA, Klumpp K, Smith DB. The application of phosphoramidite ProTide approach confers micromolar potency against hepatitis C virus in inactive agent 4'-azidoinosine: kinase bypass on a bual sugar/base modified nucleoside. Bioorg Med Chem Lett. 2009;19(11):3122-3124.

96. Yoo CB, Valente R, Congiatu C, et al. Activation of P16 gene silenced by methylation in cancer cells by phsophoramidate derivatives of 2'-deoxyzebularine. J Med Chem. 2008;52(23):7593-7601.

97. Beaulieu PL, Bos M, Bousquet Y, et al. Non-nucleoside inhibitors of the hepatitis C virus NS5B polymerase: discovery and preliminary SAR of benzimidazole derivatives. Bioorg Med Chem Lett. 2004;14(1):119-124.

98. Kukolj G, McGibbon GA, McKercher G, et al. Binding site characterization and resistance to a class of non-nucleoside inhibitors of the hepatitis C virus NS5B polymerase. J Biol Chem. 2005;280(47): 39260-39267.

99. McKercher G, Beaulieu PL, Lamarre D, et al. Specific inhibitors of HCV polymerase identified using an NS5B with lower affinity for template/primer substrate. Nucleic Acids Res. 2004;32(2): 422-431.

100. Ma H, Leveque V, De Witte A, et al. Inhibition of native hepatitis $\mathrm{C}$ virus replicase by nucleotide and non-nucleoside inhibitors. Virology. 2005;332(1):8-15

101. Kaushik-Basu N, Bopda-Waffo A, Talele TT, et al. Identification and characterization of coumestans as novel HCV NS5B polymerase inhibitors. Nucleic Acids Res. 2008;36(5):1482-1496.

102. Love RA, Parge HE, Yu X, et al. Crystallographic identification of a noncompetitive inhibitor binding site on the hepatitis $\mathrm{C}$ virus NS5B RNA polymerase enzyme. J Virol. 2003;77(13):7575-7581.

103. Wang M, Ng KK, Cherney MM, et al. Non-nucleoside analogue inhibitors bind to an allosteric site on HCV NS5B polymerase. Crystal structures and mechanism of inhibition. $J$ Biol Chem. 2003;278(11):9489-9495.

104. Howe AY, Cheng H, Thompson I, et al. Molecular mechanism of a thumb domain hepatitis $\mathrm{C}$ virus nonnucleoside RNA-dependent RNA polymerase inhibitor. Antimicrob Agents Chemother. 2006;50(12):4103-4113.

105. Le Pogam S, Kang H, Harris SF, et al. Selection and characterization of replicon variants dually resistant to thumb- and palm-binding nonnucleoside polymerase inhibitors of the hepatitis $\mathrm{C}$ virus. J Virol. 2006;80(12):6146-6154.

106. Dhanak D, Duffy KJ, Johnston VK, et al. Identification and biological characterization of heterocyclic inhibitors of the hepatitis $\mathrm{C}$ virus RNA-dependent RNA polymerase. J Biol Chem. 2002;277(41): 38322-38327.

107. Gu B, Johnston VK, Gutshall LL, et al. Arresting initiation of hepatitis $\mathrm{C}$ virus RNA synthesis using heterocyclic derivatives. J Biol Chem. 2003;278(19):16602-16607.

108. Kneteman NM, Howe AY, Gao T, et al. HCV796: a selective nonstructural protein $5 \mathrm{~B}$ polymerase inhibitor with potent anti-hepatitis $\mathrm{C}$ virus activity in vitro, in mice with chimeric human livers, and in humans infected with hepatitis C virus. Hepatology. 2009;49(3):745-752.

109. Howe AY, Cheng H, Johann S, et al. Molecular mechanism of hepatitis $\mathrm{C}$ virus replicon variants with reduced susceptibility to a benzofuran inhibitor, HCV-796. Antimicrob Agents Chemother. 2008;52(9): 3327-3338.

110. Feldstein A, Kleiner D, Kravetz D, Buck M. Severe hepatocellular injury with apoptosis induced by a hepatitis $\mathrm{C}$ polymerase inhibitor. $J$ Clin Gastroenterol. 2009;43(4):374-381.

111. Nyanguile O, Pauwels F, Van den Broeck W, et al. 1,5-benzodiazepines, a novel class of hepatitis $\mathrm{C}$ virus polymerase nonnucleoside inhibitors. Antimicrob Agents Chemother. 2008;52(12):4420-4431. 
112. Powers JP, Piper DE, Li Y, et al. SAR and mode of action of novel non-nucleoside inhibitors of hepatitis C NS5b RNA polymerase. $J$ Med Chem. 2006;49(3):1034-1046.

113. Koch U, Attenni B, Malancona S, et al. 2-(2-Thienyl)-5,6-dihydroxy4-carboxypyrimidines as inhibitors of the hepatitis $\mathrm{C}$ virus NS5B polymerase: discovery, SAR, modeling, and mutagenesis. $\mathrm{J} \mathrm{Med}$ Chem. 2006;49(5):1693-1705.

114. Summa V, Petrocchi A, Matassa VG, et al. HCV NS5b RNA-dependent RNA polymerase inhibitors: from alpha,gamma-diketoacids to 4,5dihydroxypyrimidine- or 3-methyl-5-hydroxypyrimidinonecarboxylic acids. Design and synthesis. J Med Chem. 2004;47(22):5336-5339.

115. Bellecave $P$, Cazenave $C$, Rumi J, et al. Inhibition of hepatitis $C$ virus (HCV) RNA polymerase by DNA aptamers: mechanism of inhibition of in vitro RNA synthesis and effect on HCV-infected cells. Antimicrob Agents Chemother. 2008;52(6):2097-2110.

116. Watashi K, Ishii N, Hijikata M, et al. Cyclophilin B is a functional regulator of hepatitis $\mathrm{C}$ virus RNA polymerase. Mol Cell. 2005;19(1):111-122.

117. Chatterji U, Bobardt M, Selvarajah S, et al. The isomerase active site of cyclophilin A is critical for hepatitis $\mathrm{C}$ virus replication. J Biol Chem. 2009;284(25):16998-17005.

118. Liu Z, Yang F, Robotham JM, Tang H. Critical role of cyclophilin A and its prolyl-peptidyl isomerase activity in the structure and function of the hepatitis $\mathrm{C}$ virus replication complex. $J$ Virol. 2009;83(13):6554-6565.

119. Chatterji U, Bobardt M, Lim P, Gallay P. Cyclophilin A-independent recruitment of NS5A and NS5B into HCV replication complexes. J Gen Virol. 2010; Jan 27. [Epub ahead of print].

120. Hanoulle X, Badillo A, Wieruszeski JM, et al. Hepatitis C virus NS5A protein is a substrate for the peptidyl-prolyl cis/trans isomerase activity of cyclophilins A and B. J Biol Chem. 2009;284(20):13589-13601.

121. Liu Z, Robida JM, Chinnaswamy S, et al. Mutations in the hepatitis $\mathrm{C}$ virus polymerase that increase RNA binding can confer resistance to cyclosporine A. Hepatology. 2009;50(1):25-33.

122. Hopkins S, Scorneaux B, Huang Z, et al. SCY-635: a novel nonimmunosuppressive analog of cyclosporin A that exhibits potent inhibition of hepatitis C virus RNA replication in vitro. Antimicrob Agents Chemother. 2010;54(2):660-672.

123. Ma S, Boerner JE, TiongYip C, et al. NIM811, a cyclophilin inhibitor, exhibits potent in vitro activity against hepatitis $\mathrm{C}$ virus alone or in combination with alpha interferon. Antimicrob Agents Chemother. 2006;50(9):2976-2982.
124. Watashi K, Inoue D, Hijikata M, Goto K, Aly HH, Shimotohno K. Anti-hepatitis $\mathrm{C}$ virus activity of tamoxifen reveals the functional association of estrogen receptor with viral RNA polymerase NS5B. J Biol Chem. 2007;282(45):32765-32772.

125. Ludmerer SW, Graham DJ, Boots E, et al. Replication fitness and NS5B drug sensitivity of diverse hepatitis C virus isolates characterized by using a transient replication assay. Antimicrob Agents Chemother. 2005;49(5):2059-2069.

126. Heck JA, Lam AM, Narayanan N, Frick DN. Effects of mutagenic and chain-terminating nucleotide analogs on enzymes isolated from hepatitis $\mathrm{C}$ virus strains of various genotypes. Antimicrob Agents Chemother. 2008;52(6):1901-1911.

127. Herlihy KJ, Graham JP, Kumpf R, Patick AK, Duggal R, Shi ST. Development of intergenotypic chimeric replicons to determine the broad-spectrum antiviral activities of hepatitis $\mathrm{C}$ virus polymerase inhibitors. Antimicrob Agents Chemother. 2008;52(10):3523-3531.

128. Pauwels F, Mostmans W, Quirynen LM, et al. Binding-site identification and genotypic profiling of hepatitis $\mathrm{C}$ virus polymerase inhibitors. J Virol. 2007;81(13):6909-6919.

129. Le Pogam S, Seshaadri A, Kosaka A, et al. Existence of hepatitis C virus NS5B variants naturally resistant to non-nucleoside, but not to nucleoside, polymerase inhibitors among untreated patients. J Antimicrob Chemother. 2008;61(6):1205-1216.

130. Donlin MJ, Cannon NA, Aurora R, et al. Contribution of genomewide $\mathrm{HCV}$ genetic differences to outcome of interferon-based therapy in Caucasian American and African American patients. PLoS One. 2010;5(2):e9032.

131. Aurora R, Donlin MJ, Cannon NA, Tavis JE. Genome-wide hepatitis C virus amino acid covariance networks can predict response to antiviral therapy in humans. J Clin Invest. 2009;119(1):225-236.

132. HCV Databases. The Hepatitis C Database Project. 2006. Available from: http://hcv.lanl.gov/content/index. Accessed May 2, 2010.

133. NCBI. National Center for Biotechnology Information Database. 2009 Oct 28. Available from: http://www.ncbi.nlm.nih.gov/.Accessed May 2, 2010.

134. Rydberg EH, Cellucci A, Bartholomew L, et al. Structural basis for resistance of the genotype $2 \mathrm{~b}$ hepatitis $\mathrm{C}$ virus NS5B polymerase to site A non-nucleoside inhibitor. J Mol Biol. 2009; (390):1048-1059.

135. Flint M, Mullen S, Deatly AM, et al. Selection and characterization of hepatitis $\mathrm{C}$ virus replicons dually resistant to the polymerase and protease inhibitors HCV-796 and boceprevir (SCH 503034). Antimicrob Agents Chemother. 2009;53(2):401-411.
Virus Adaptation and Treatment

\section{Publish your work in this journal}

Virus Adaptation and Treatment is an international, peer-reviewed open access journal focusing on the study of virology, viral adaptation and the development and use of antiviral drugs and vaccines to achieve improved outcomes in infection control and treatment. The journal welcomes original research, basic science, clinical \& epidemiological

\section{Dovepress}

studies, reviews \& evaluations, expert opinion and commentary, case reports and extended reports. The manuscript management system is completely online and includes a very quick and fair peer-review system, which is all easy to use. Visit http://www.dovepress.com/ testimonials.php to read real quotes from published authors. 